\title{
IMPROVING THE RESISTANCE OF STRUCTURES TO EARTHQUAKES
}

\author{
R. Park $^{1}$
}

\section{Hopkins Lecture - 16 August 2000}

\begin{abstract}
The past occurrence of earthquakes in New Zealand and the likelihood of a major earthquake in Christchurch are considered. The causes of damage by earthquakes are discussed and typical possible types of damage to building and bridge structures are described with reference to the 1995 Kobe earthquake. The design of building and bridge structures for earthquake resistance by the ductile design approach is covered, including performance criteria, structural configuration, design seismic forces, mechanisms of post-elastic deformation, capacity design, detailing of reinforcement for ductility and control of deflections. Design using base isolation and mechanical energy dissipating devices is also outlined. The extensive use of precast concrete in buildings in New Zealand is described. Finally the seismic assessment and upgrading of old structures and the earthquake resistance of lifelines of communities (transportation, utilities and communications) are briefly considered.
\end{abstract}

\section{FOREWORD}

On 31 January 1978, Professor H J Hopkins retired after 27 years as Head of the Department of Civil Engineering at the University of Canterbury. In this role he developed a Department of high international standing and in so doing he made a major contribution to the Engineering Profession in New Zealand. In order to recognise his distinguished service to the University and to the Profession as a whole, the University of Canterbury and the Institution of Professional Engineers New Zealand have inaugurated a yearly lecture called the "Hopkins Lecture".

The Hopkins Lecture is given by a distinguished speaker from overseas or New Zealand on a subject of interest to members of the Engineering Profession. Expenses are met from interest accrued by a trust fund set up for the purpose which has been contributed by members of the Profession, University Staff and others.

The purpose of the lecture is to encourage discussion of engineering matters within the Profession and to promote public understanding of engineering issues. The intention is that the lectures should combine depth of scholarship with breadth of interest; for in so doing they will follow the approach epitomised by the late Professor Hopkins himself.

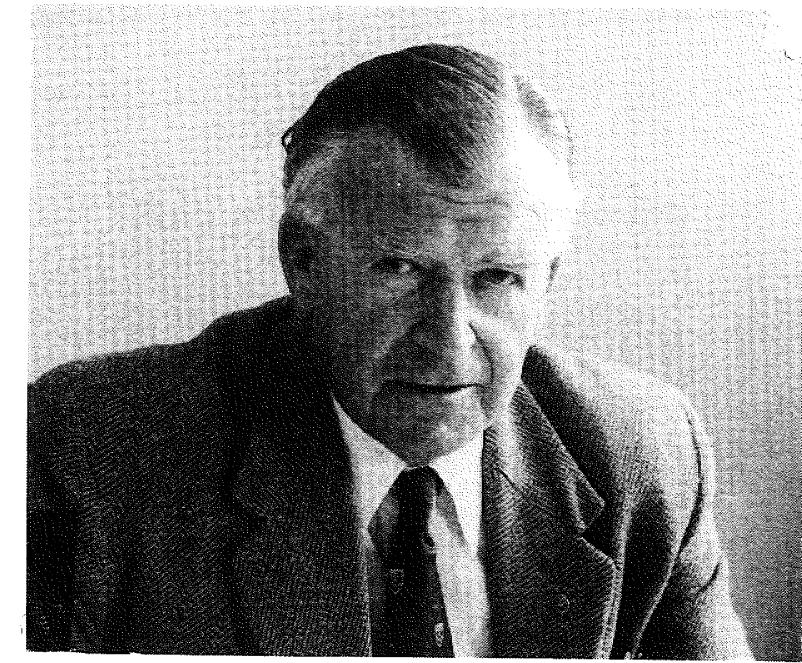

Professor Henry James Hopkins (1912-86; University of Western Australia : BE, BSc; Rhodes Scholar, Brasenose College, University of Oxford : MA, Senior lecturer in Civil Engineering, University of Western Australia, 1948-51; Professor and Head of Civil Engineering, University of Canterbury, 1951-78; President New Zealand Institution of Engineers 1966-67).

\footnotetext{
${ }^{1}$ Emeritus Professor, Department of Civil engineering, University of Canterbury, Christchurch, NZ. (Life Member \& Past President).
} 


\section{Personal Note by Emeritus Professor R Park:}

I took over the Headship of the Department of Civil Engineering of the University of Canterbury in 1978 when Professor Hopkins retired. I have much to thank Harry Hopkins for. He was my Professor when I was an undergraduate student. $\mathrm{He}$ attracted me back to the University of Canterbury to undertake postgraduate studies after I had worked a short period with the Christchurch Drainage Board. My masters degree was under his supervision and my love for concrete as a building material was the result of his enthusiasm. He remained my mentor for many years while I was a member of staff of the Department of Civil Engineering.

\section{EARTHQUAKES AS A NATURAL HAZARD}

\section{$1.1 \quad$ General}

Much of the surface of the earth is subjected to earthquakes from time to time. An earthquake is a spasm of ground shaking originating from part of the earth's crust.

The Maori god of earthquakes and volcanoes is Ruaumoko. Maori mythology records that Ruaumoko - the last of a family of seventy - was still at the breast when the Earthmother was turned over on her face by her other sons to improve the weather conditions, and thus he was carried under. Ruaumoko is stated to be hostile to man and now and then he sends an earthquake or a volcanic disturbance to destroy him. Ruaumoko is the symbol of both the International Association for Earthquake Engineering and of the New Zealand Society for Earthquake Engineering.

Scientific observation gives us further explanation. The crust of the earth is broken up into number of rigid plates of rock between 15 and 100 kilometres thick which are moving very slowly at about 20-120 mm per year relative to each other (see Fig. 1). This jostling between the plates causes stresses to build up in the edge regions of the plates. Earthquakes generally occur due to a sudden release of energy when the accumulated strain at some part near the edges of plates becomes so great that rupture of the rock occurs along the plane of a fault. The resulting sudden movement along the fault causes the transmission of the complex set of shock waves through the earth that we describe as an earthquake (see Fig. 2). The fault can break through to the earth's surface. The place of initial rupture on the fault is known as the focus of the earthquake. The epicentre of the earthquake is the point on the earth's surface directly above the focus. Most of the world's earthquakes occur in the edge regions of the plates but intraplate earthquakes can also occur at faults away from the edges of the plates.

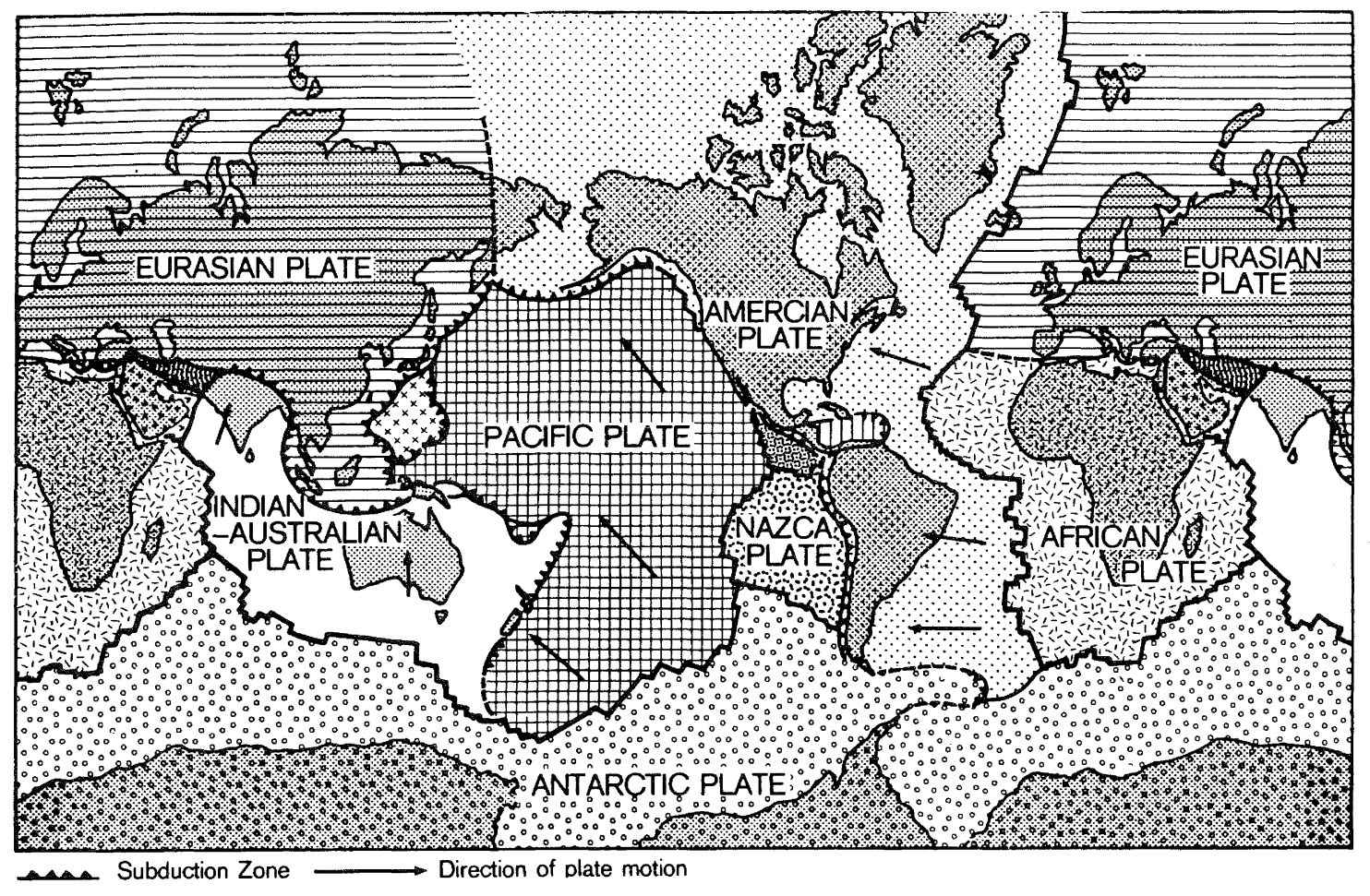

Fig. 1: Coastal plate boundaries of the earth [1]. 


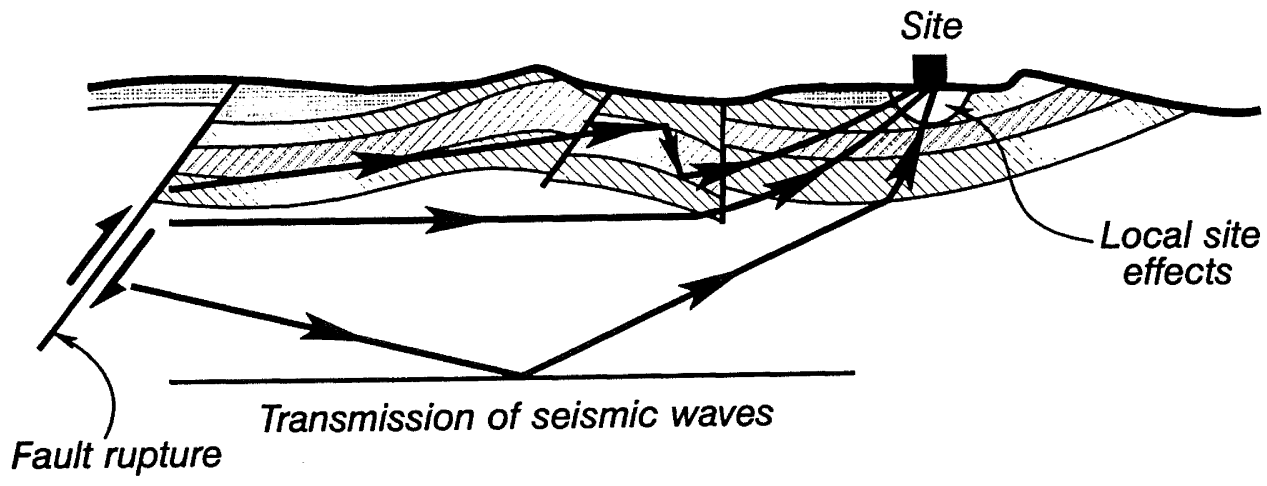

Fig. 2 Transmission of seismic waves from the focus of an earthquake to a site.

The "strength" of an earthquake is defined in two ways:

1. The total strength of the earthquake, as related to the energy released at the source is called the magnitude, which is independent of the place of observation. The most widely used magnitude scale is that named after Charles Richter and is denoted by $M$ or $M_{L} . \quad A M<5$ earthquake does not cause significant damage in New Zealand. A $\mathrm{M}=7$ earthquake can cause severe damage close to its epicenter. A $M=8$, or more, earthquake is a very big earthquake indeed. The Richter scale is logarithmic. An increase in one Richter magnitude means that 27 times more energy is released at the focus of the earthquake. Therefore a $M$ $=7$ earthquake releases 730 times as much energy ( 27 $x$ 27) than a $M=5$ earthquake. The Richter magnitudes of some recent major damaging earthquakes that have occurred overseas are shown in Table 1.

2. The strength of an earthquake at a given locations is called the intensity. The intensity depends on the distance from the epicentre, the nature of the intervening terrain and other factors. The most widely used intensity scale is the Modified Mercalli scale (commonly denoted as MM) which has twelve grades I-XII, which reflect the intensity according to felt effects and damage. Intensity MMI is felt by very few and intensity MMXII is nearly total damage.

Table 1 : Some recent major damaging earthquakes that have occurred overseas

\begin{tabular}{|c|l|c|c|}
\hline Year & \multicolumn{1}{|c|}{ Country } & $\begin{array}{c}\text { Richter } \\
\text { Magnitude }\end{array}$ & Number of Deaths \\
\hline 1976 & Tangshan, China & 8.0 & 240,000 \\
1985 & Coast of Chile & 7.8 & 147 \\
1985 & Mexico City & 8.1 & 10,000 \\
1989 & Loma Prieta, California & 7.1 & 62 \\
1990 & Lutzon, Philippines & 7.8 & 12,000 \\
1994 & Northridge, California & 6.4 & 59 \\
1995 & Kobe, Japan & 7.1 & 6,500 \\
1999 & Turkey & 7.4 & 18,000 \\
1999 & Taiwan & 7.6 & 2,000 \\
\hline
\end{tabular}
New Zealand

The circum-Pacific seismic belt, on which New Zealand is situated, is responsible for about $80 \%$ of the world's earthquakes. Some examples of large shallow earthquakes that have occurred in New Zealand since the middle of the last century are listed in Table 2 and shown in Figure 3. 
Table 2 Examples of Shallow Earthquakes with $M \geq 6.8$ which have occurred in New Zealand since the 1840's [2]

\begin{tabular}{|l|l|r|}
\hline 1843 & Wanganui & $\mathrm{M} \geq 7.5$ \\
1848 & Marlborough & $\mathrm{M}=7.1$ \\
1855 & South West Wairarapa & $\mathrm{M}=8.1$ \\
1888 & North Canterbury & $\mathrm{M}=7.0$ \\
1897 & Wanganui & $\mathrm{M}=7.0$ \\
1901 & Cheviot & $\mathrm{M}=7.0$ \\
1904 & Off Cape Turnagain & $\mathrm{M}=7.5$ \\
1914 & East Cape Peninsula & $\mathrm{M}=7.0-7.5$ \\
1921 & Hawke's Bay & $\mathrm{M}=7.0$ \\
1922 & Arthur's Pass & $\mathrm{M}=6.9$ \\
1929 & Buller & $\mathrm{M}=7.8$ \\
1931 & Hawke's Bay & $\mathrm{M}=7.9$ \\
1932 & Wairoa & $\mathrm{M}=6.8$ \\
1934 & Pahiatua & $\mathrm{M}=7.6$ \\
1942 & South Wairarapa & $\mathrm{M}=7.0$ and 7.1 \\
1950 & South of South Island & $\mathrm{M}=7.0$ and 7.3 \\
1953 & Bay of Plenty & $\mathrm{M}=7.1$ \\
1958 & Bay of Plenty & $\mathrm{M}=6.9$ \\
1960 & Fiordland & $\mathrm{M}=7.0$ \\
1968 & Inangahua & $\mathrm{M}=7.0$ \\
\hline
\end{tabular}

New Zealand has been fortunate in that since the Hawke's Bay earthquake of 3 February 1931, which had a Richter magnitude of 7.9 and caused 256 deaths, major earthquakes have not occurred close to large population centres in this country. Therefore, damage from large earthquakes has not affected a great proportion of the population of New Zealand for about 70 years. For example, the Inangahua earthquake of 24 May 1968 had a magnitude of 7.0 on the Richter scale but occurred in a sparsely populated part of New Zealand and there were only three deaths. Note that since that earthquake in 1968 there has not been an earthquake with Richter magnitude $M \geq 6.8$ with epicenter on New Zealand. The magnitude of the damaging Edgecumbe earthquake in the Bay of Plenty in 1987 was $M=6.3$. Clearly New Zealand has been undergoing a period of unusual seismic quiescence. Table 2 indicates that on average New Zealand normally experiences an earthquake with $M \geq 7.0$ about every 8 years.

The Institute of Geological and Nuclear Sciences operates a network of 310 strong-motion recorders throughout New Zealand [3] which measure the accelerations of the ground and the accelerations induced in structures.
The Alpine fault in the South Island is probably New Zealands most hazardous fault [3]. Evidence gathered during the last few years suggests an average return period of earthquakes along the Alpine fault of around 200 years [4]. The last rupture on it was nearly 300 years ago in 1717 [4]. Clearly it is overdue for what may be a magnitude $M=8$ earthquake. It is estimated that displacements of 1-3 m vertically and $8 \mathrm{~m}$ horizontally could occur along the Alpine Fault. The Wellington fault also, has a high hazard level with an average return period of about 600 years. It is estimated that displacements of $1 \mathrm{~m}$ vertically and $4 \mathrm{~m}$ horizontally could occur along the Wellington Fault. It is about 400 years since the last rupture along it but it has a much higher level of risk of damage associated with it since it passes through the cities of Wellington, Lower Hutt and Upper Hutt. 


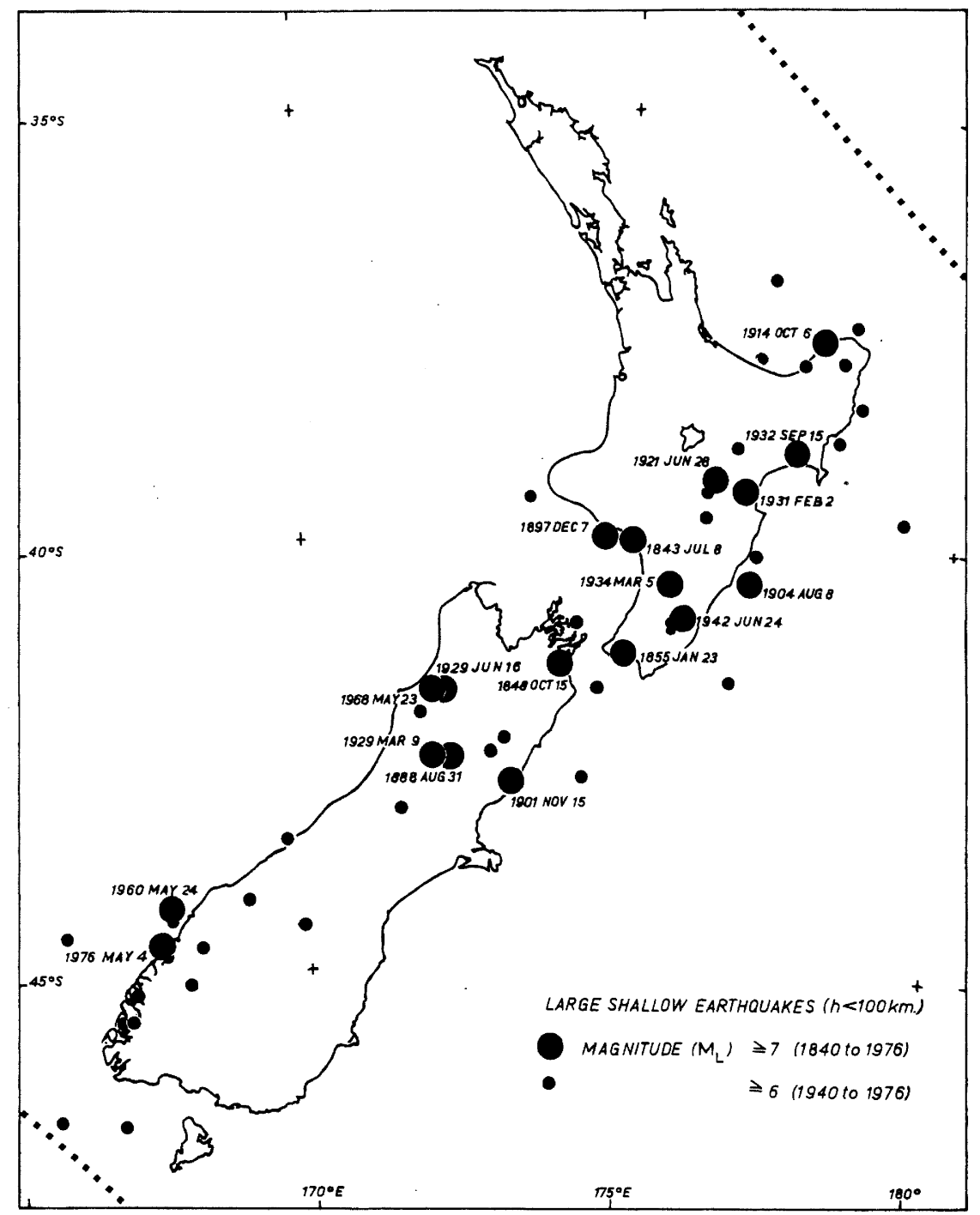

Fig. 3: Large Shallow Earthquakes, which have occurred in New Zealand during 1840-1976 [2].

Known active faults in Canterbury are shown in Fig. 4. The Christchurch Engineering Lifelines Group in 1997 [5] after a study of the information on the seismicity of Christchurch, mainly by Elder et al [6], concluded that a major earthquake with a felt intensity of VIII to IX (causing considerable damage to ordinary buildings) could be expected for Christchurch with a return period of about 150 years. Such shaking would most likely be caused by a moderately-large to large earthquake in the Canterbury foothills or North Canterbury. A very large earthquake on the Alpine fault would also be likely to produce these shaking intensities or greater.

It is evident that earthquake preparedness and mitigation measures are essential in Christchurch, as for all parts of New Zealand.

\section{TYPICAL DAMAGE CAUSED BY EARTHQUAKES}

\section{$2.1 \quad$ The damaging effects of earthquakes}

The consequences of severe earthquakes are the injury and loss of life of people, the costs of repair of damage to structures and contents, and the costs of disruption of business and other activities.

Almost 9,000 people were killed around the world in earthquakes during 1998, which is close to the long-term average of about 10,000 per year. 


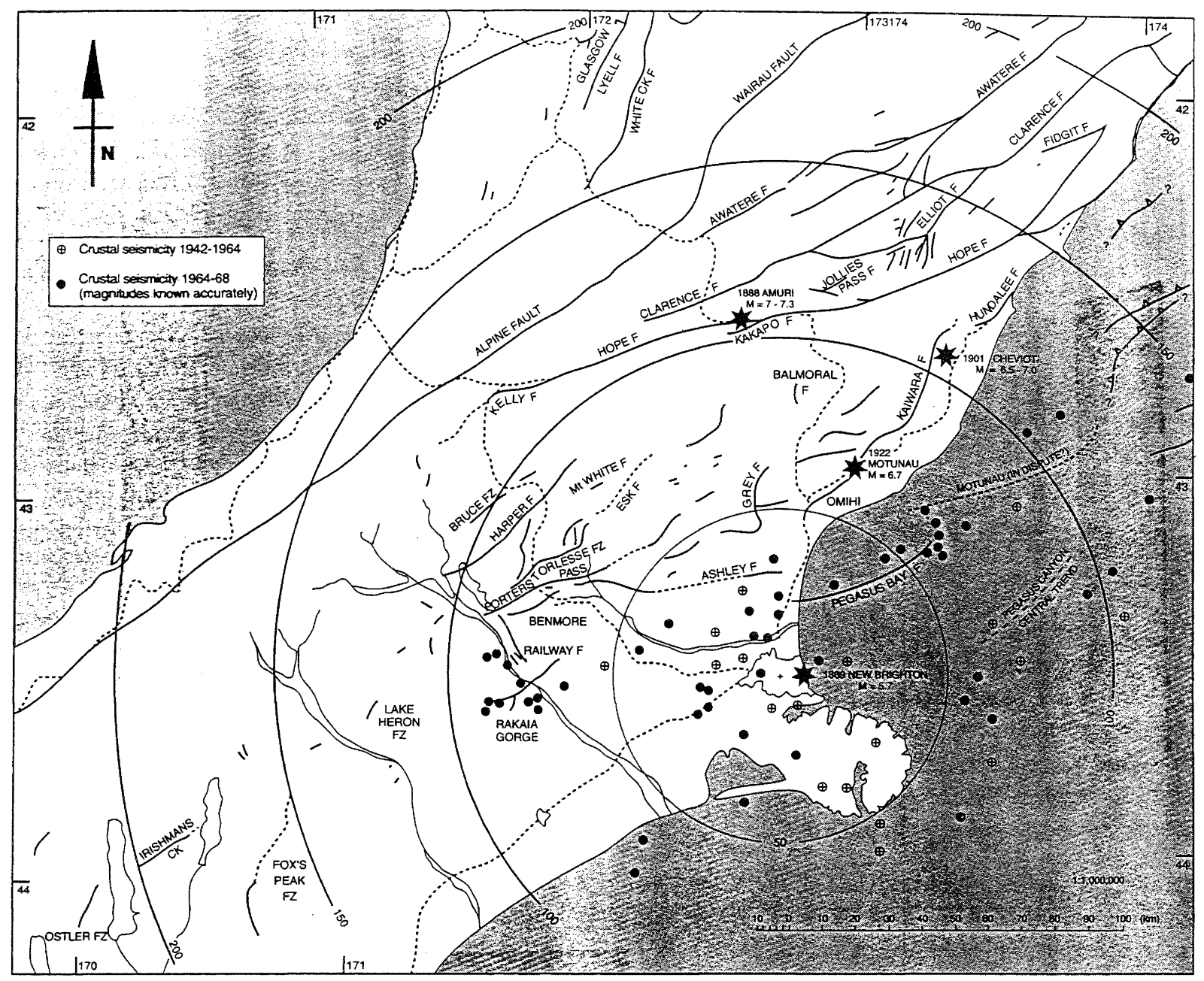

Fig. 4: Active faults within $200 \mathrm{~km}$ of Christchurch [5].

The damage and disruption caused by earthquakes throughout the world has been considerable. For example the cost of the building loss as a result of the Northridge earthquake of 1994 in California was in the order of $\$ 20$ billion US and of the Kobe earthquake of 1995 in Japan was at least 10 times greater.

Shallow earthquakes with a focus within 30 or $40 \mathrm{~km}$ of the surface of the earth are more damaging than earthquakes with a deeper focus due to the reduction of ground shaking with distance. Similarly, the damaging effects of earthquakes reduces with horizontal distance from the epicenter according to attenuation relationships for given depth of focus.

The damaging effects of earthquakes are threefold:

1. The ground shaking induces vibrations in the structure and the resulting deformation can cause significant damage and possibly collapse of the structure. The shaking in the horizontal directions is the most damaging for structures. Dynamic analysis can be used to determine from the acceleration records of ground shaking the maximum accelerations, velocities and displacements imposed on various elements of a structure. For example, response spectra giving the maximum acceleration of a mass on top of columns behaving elastically for various natural periods of vibration of the structure can be computed for a given record of earthquake ground shaking. This enables the maximum horizontal forces on the structure during the earthquake to be calculated. The acceleration record of earthquake ground shaking is modified by the type of soil on which the structure is sited. For soft soils the earthquake vibrations can be significantly amplified and hence the shaking of structures sited on soft soils can be much greater than for structures sited on bedrock.

2. The ground shaking can result in deformations of the ground which cause damage. One example is landslides in sloping ground. Another is relative movement along and across surface fault lines and uplift, each of which can be up to several metres. For example, the Hawke's Bay earthquake of 1931 caused nearly 2 metres of permanent uplift at Napier. The 
ground shaking can also cause liquefaction of the ground. This phenomenon occurs when fine saturated sand compacts as a result of earthquake shaking resulting in an increase in pore water pressure and a decrease of soil strength. The extent of liquefaction is greater for earthquakes of long duration. Liquefaction can result in foundation settlement and lateral spreading of soils resulting in tilting or even overturning of buildings.

3. Damage can be caused by tsunamis (tidal waves) as a result of shallow earthquakes or landslides near the coast and seiches (lake water waves). The South West Wairarapu earthquake of 1885 caused a tsunami over 10 metres high that swept both sides of Cook Strait. the early years of European settlement

New Zealand was subjected to a number of major earthquakes in the early years of European settlement, as is evident from Fig. 3 and Table 2. Figure 5 shows some typical damage to buildings in Wellington as a result of the 1848 Marlborough earthquake, which had a Richter magnitude of 7.1. These early warnings that special building precautions were needed for earthquake resistance went largely unheeded by settlers who had come from nonearthquake countries and had brought traditional European building procedures with them.

The 1931 Hawke's Bay earthquake caused extensive damage to buildings. Fire followed the earthquake rapidly, completing the devastation caused by the earthquake.
Figures 6 and 7 show close-up views of some of the business centres of Napier after the earthquake and fire and give an impression of the resulting devastation. Whereas load bearing masonry structures performed badly in the Hawke's Bay earthquake, buildings with reinforced concrete or structural steel frames on the whole suffered less structural damage and withstood the earthquake with remarkable success. In New Zealand this led to a shift in emphasis of building type from load bearing brick to framed buildings.

As a result of the Hawke's Bay earthquake a Buildings Regulation Committee, under the Chairmanship of Professor JEL Cull of Canterbury College, was set up by Government with instructions "to prepare a report embodying such recommendations as it thought fit, with a view to improving the standard of building construction in the Dominion in relation to earthquake resistance". The recommendations led to the 1935 Standard Model Building By-Law, which required design for a horizontal force equal to at least 0.1 of the weight carried by the building. The weight carried by the building was defined as the dead load plus a specified proportion of the live load. Stresses found by elastic (straight line) theory due to this earthquake loading plus vertical gravity loading were not permitted to exceed the working stresses allowed for vertical load alone by more than $25 \%$ in the case of reinforced concrete. It emphasized the importance of having brick and other types of walls securely tied together at the level of each floor, and also the importance of inter-connecting all foundation footings. It required that the structural system resisting horizontal loading be symmetrically located about the centre of mass of the building or else proper provision made for torsional moment on the building. Seismic design standards in New Zealand continued to advance since 1935 .
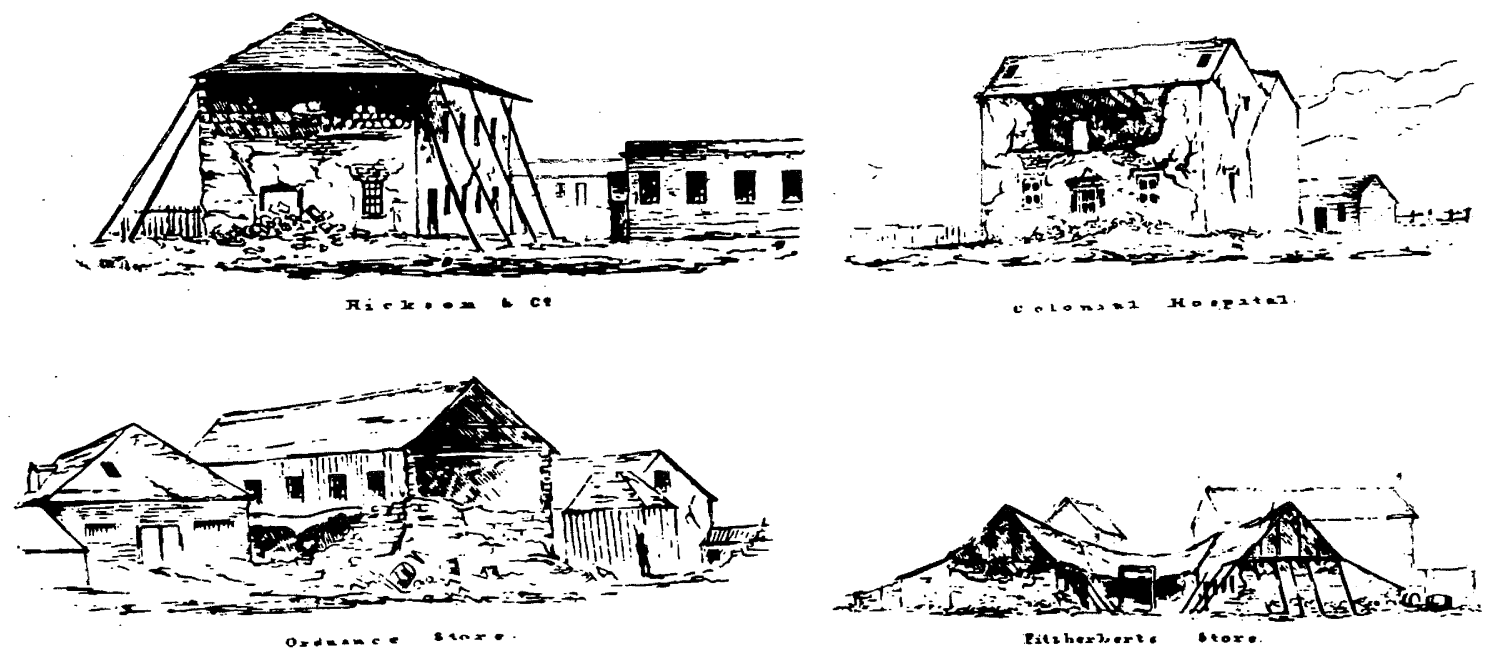

Fig. 5: Sketches of some damaged buildings in Wellington as a result of the 1848 Marlborough Earthquake (Alexander Turnbull Library, Wellington). 


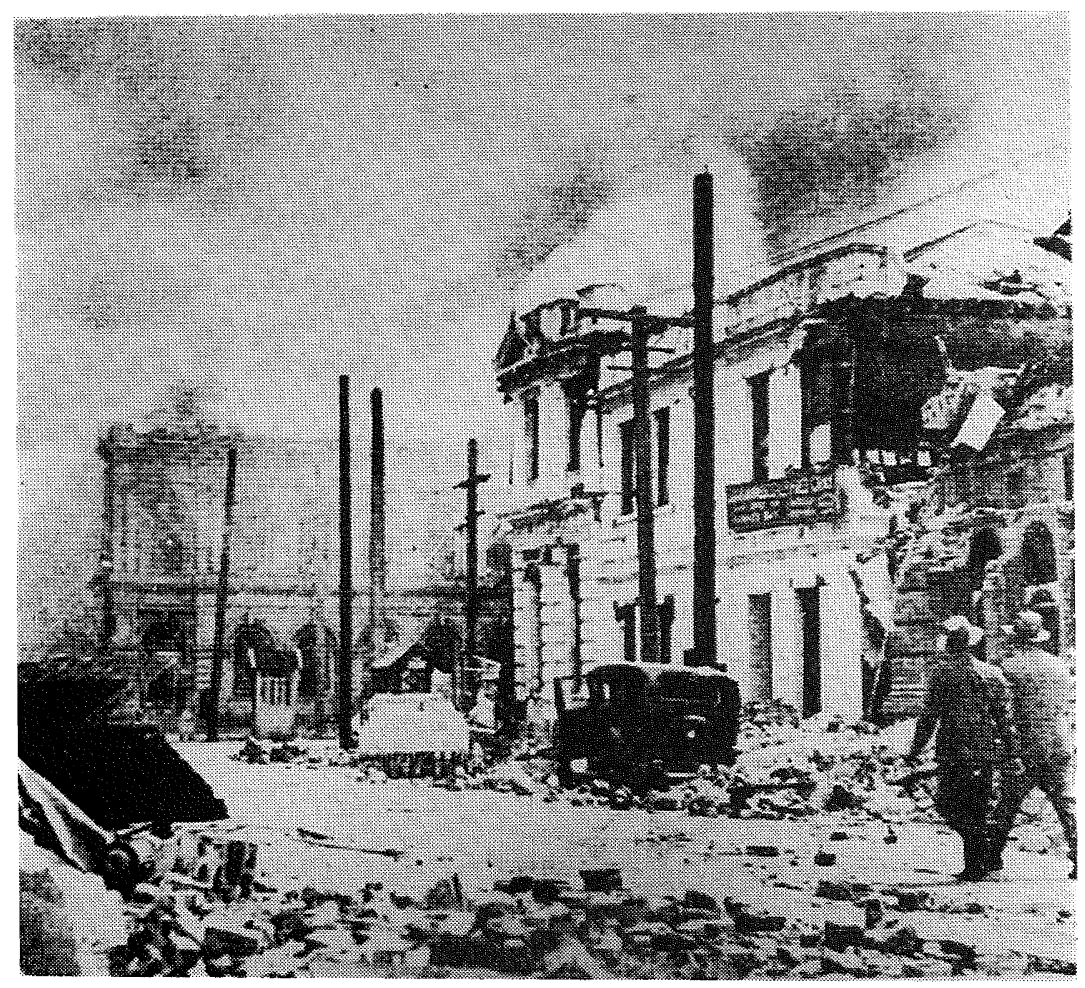

Fig 6: Damage at Napier as a result of the 1931 Hawke's Bay Earthquake (Alexander Turnbull Library, Wellington).

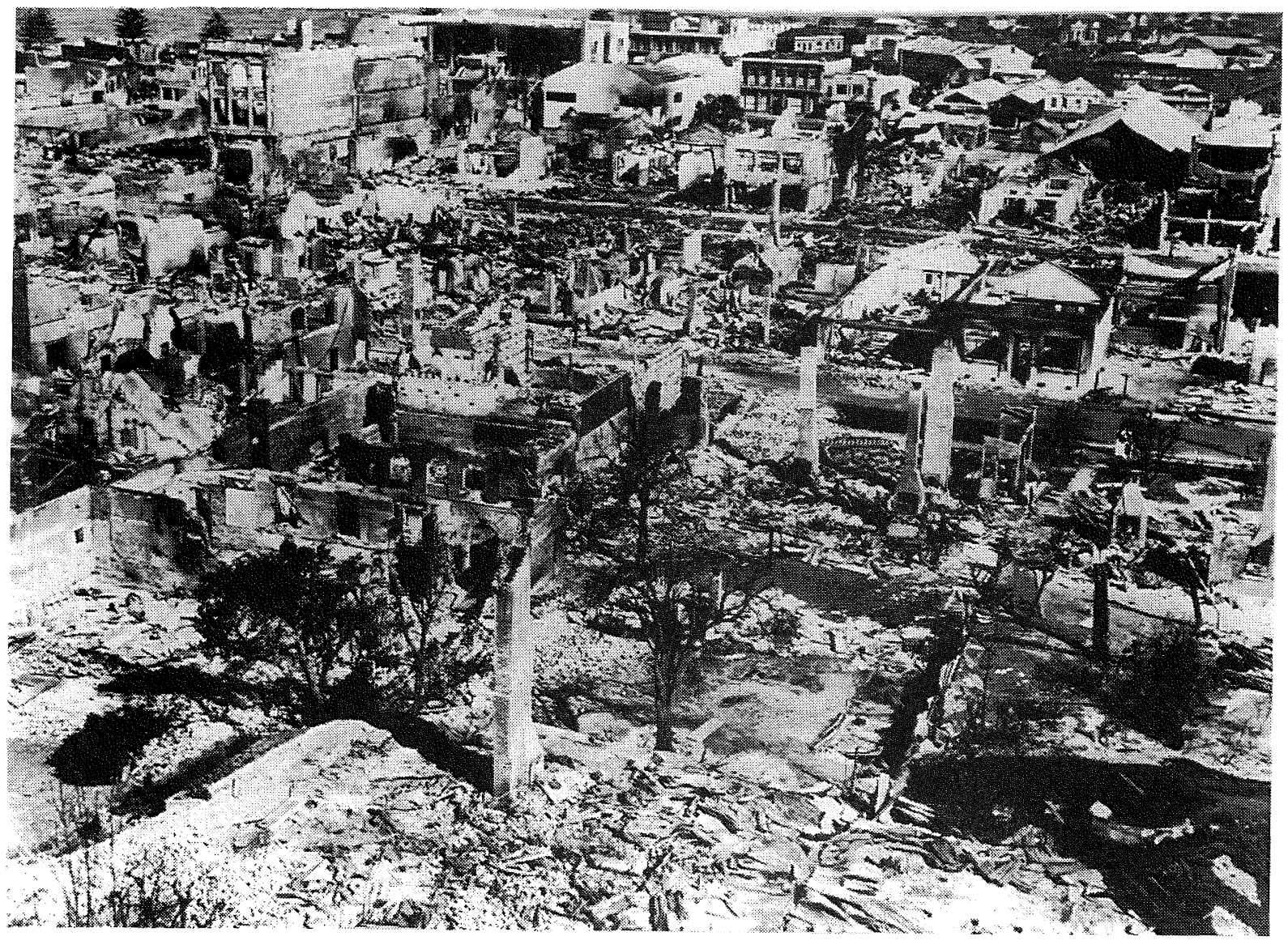

Fig 7: Damage at Napier as a result of the 1931 Hawke's Bay Earthquake (Alexander Turnbull Library, Wellington). 


\section{Damage to structures caused by the Kobe Earthquake}

\subsubsection{General}

As a result of the absence of major earthquakes from urban areas of New Zealand during the last 70 years, our experience of the performance of building construction in developed countries during that period has come mainly from overseas earthquakes in the United States and Japan. In reviewing typical damage to structures caused by earthquakes the effects of the earthquake which occurred in Kobe, Japan (also referred to as the Great Hanshin earthquake or the Hyogo-ken Nanbu earthquake) on 17 January 1995 will be reviewed [7]. The Kobe earthquake probably provides the strongest parallels for New Zealand of any overseas earthquake this century. The Kobe earthquake had a Richter magnitude of $M=7.2$ and occurred with its epicenter located about 20 kilometres to the south-west of the coastal part of Kobe. The depth of the source of the earthquake was 16 kilometres. The severe ground motions in Kobe lasted for about 20 seconds. The maximum horizontal ground acceleration was about $0.85 \mathrm{~g}$. The city of Kobe has a population of 1.5 million. Over 1,000 buildings either were severely damaged or collapsed. The death toll was approximately 6,500 people. A great deal of liquefaction occurred under the coastal reclamation and former beach areas of the city.

\subsubsection{Damage to buildings}

In 1981 the building code of Japan experienced its largest revision since its first version of 1924 . Buildings designed to the current 1981 code were found to perform very well on the whole during the Kobe earthquake. The damage was almost entirely to the older stock of buildings where the general types of failure were:

\section{(a) Tilting or overturning}

Tilting of buildings, and even overturning (see Fig. 8), occurred in some cases in the most devastated areas of the city. The columns of the overturned buildings parted from their foundations.

\section{(b) Soft storey collapses}

The predominant mode of collapse of pre-1981 buildings was of the soft storey type due to failure of the columns of one storey. Many soft storey collapses were due to failure of the first storey columns (for example, see Fig. 9). These failures occurred due to strong beam-weak column behaviour of moment resisting frames, lack of ductility of columns and failure of brace to frame connections in braced systems.

However, many soft storey collapses also occurred due to the failure of columns in an intermediate storey up the height of the building (see Fig. 10). A particularly tragic example was the Municipal Hospital in the west of Kobe which had a soft storey failure in the $5^{\text {th }}$ storey and 49 people were killed in that storey. (c)

Other types of general failure

Other general types of failure observed were due to torsion (twisting) of structures on street corners which were unsymmetrical in structural plan, such as due to walls only along two adjacent sides of the building (see Fig. 11) and pounding of adjacent structures of different stiffnesses.

For reinforced concrete structures the particular problems for structural elements and connections were due to poor detailing of reinforcement leading to shear failures, brittle compression failures of concrete, buckling of compressed longitudinal reinforcement, and anchorage failure in columns and beam-column connections (see Fig. 12).

For structural steel the particular problems for elements and connections were due to inadequate welding leading to fracture of the welds, fracture of brittle steel members, buckling of compression members, and inadequate provision of a load path through beam-column connections (see Fig. $13)$.

\section{$2.4 \quad$ Damage to bridges}

Major revisions were made to the Japanese highway bridge design code in 1980. Elevated bridge structures designed to the 1980 bridge code generally performed well during the Kobe earthquake. Many elevated bridge structures designed prior to the 1980 code performed badly. For example, major damage occurred to bridge bearings, seismic restrainers and road joints. Some spans fell due to liquefaction causing lateral spreading of piers located adjacent to waterways (see Fig. 14). Bridge piers were often heavily damaged and collapsed in a number of regions of the city (see Fig. 15). Tilting of some piers occurred due to movement of the foundation.

Several types of failure were observed for reinforced concrete piers: flexural failure of columns of piers at the base due to inadequate transverse reinforcement for concrete confinement and restraint of longitudinal bar against buckling, flexural failure of columns of piers at section above the base due to longitudinal bar cut-off, shear failure of pier columns due to inadequate transverse reinforcement and shear failure of pier cap beams due to inadequate transverse reinforcement.

Several types of failure were observed for structural steel piers: buckling of steel plates of box columns at points of maximum compressive stress and maximum wall slenderness, and brittle tension failure of steel circular hollow columns. 


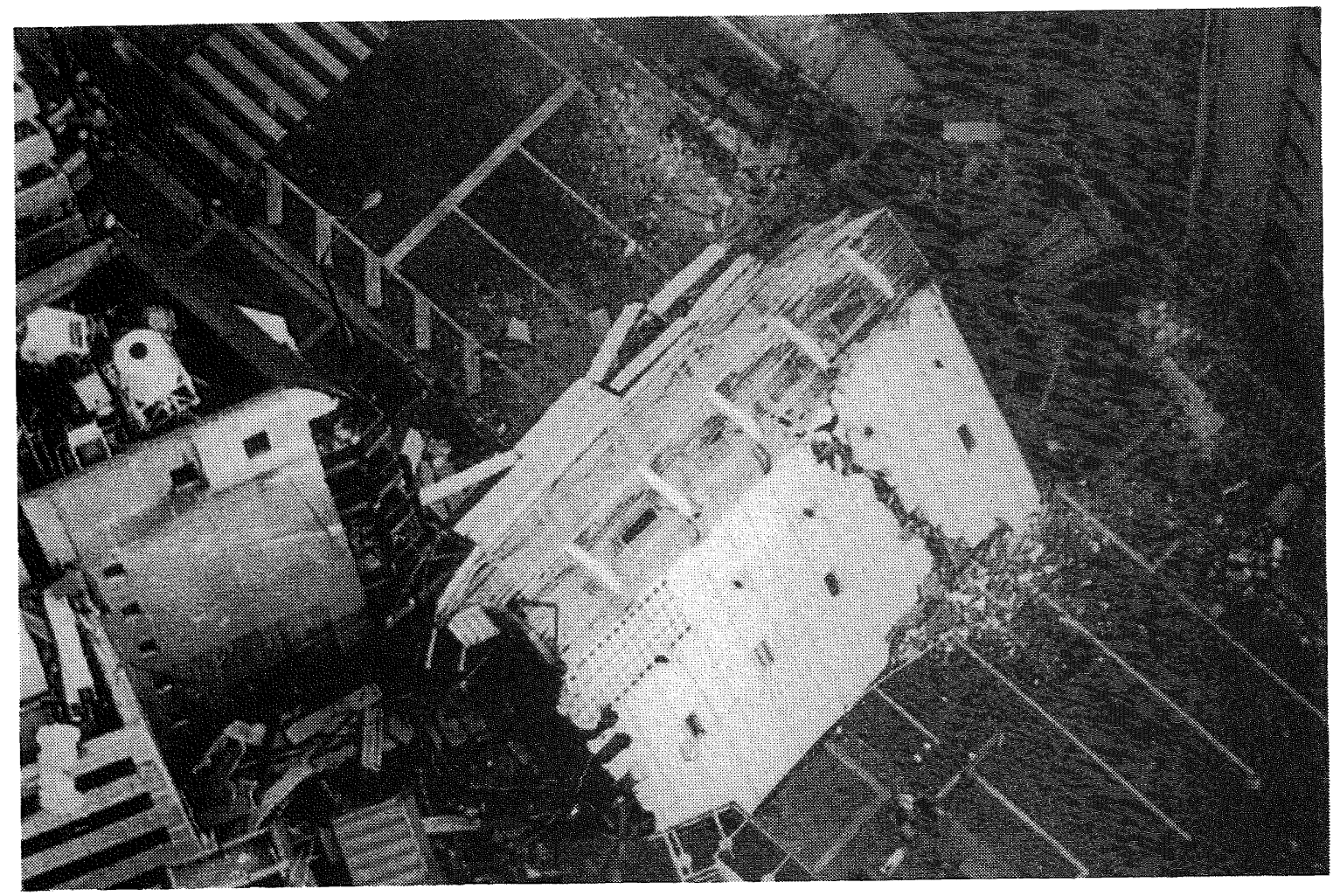

Fig. 8: Overturned building lying across a street (Kobe, 1995).

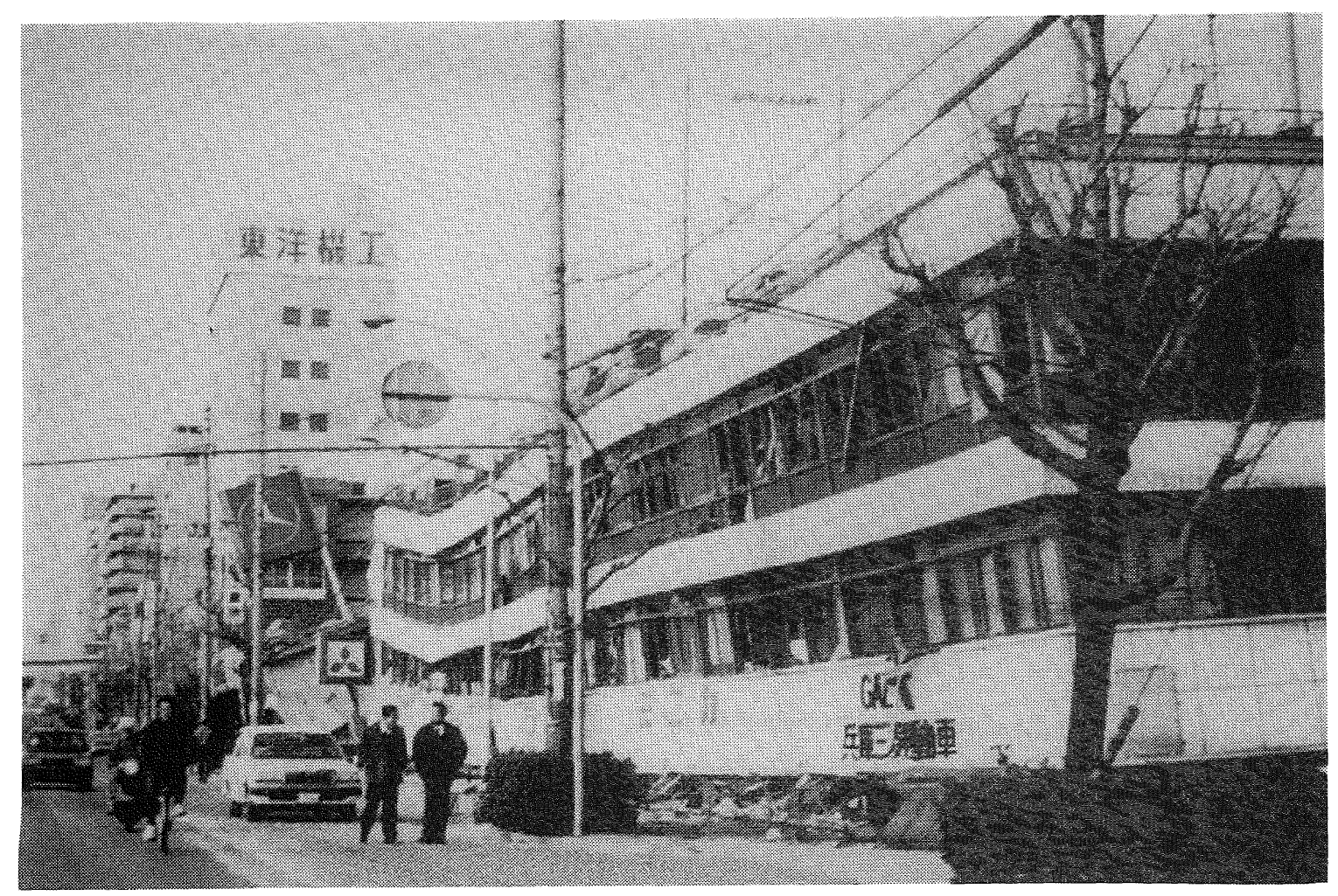

Fig. 9: Soft storey collapse of the first storey of a departmental store (Kobe, 1995). 


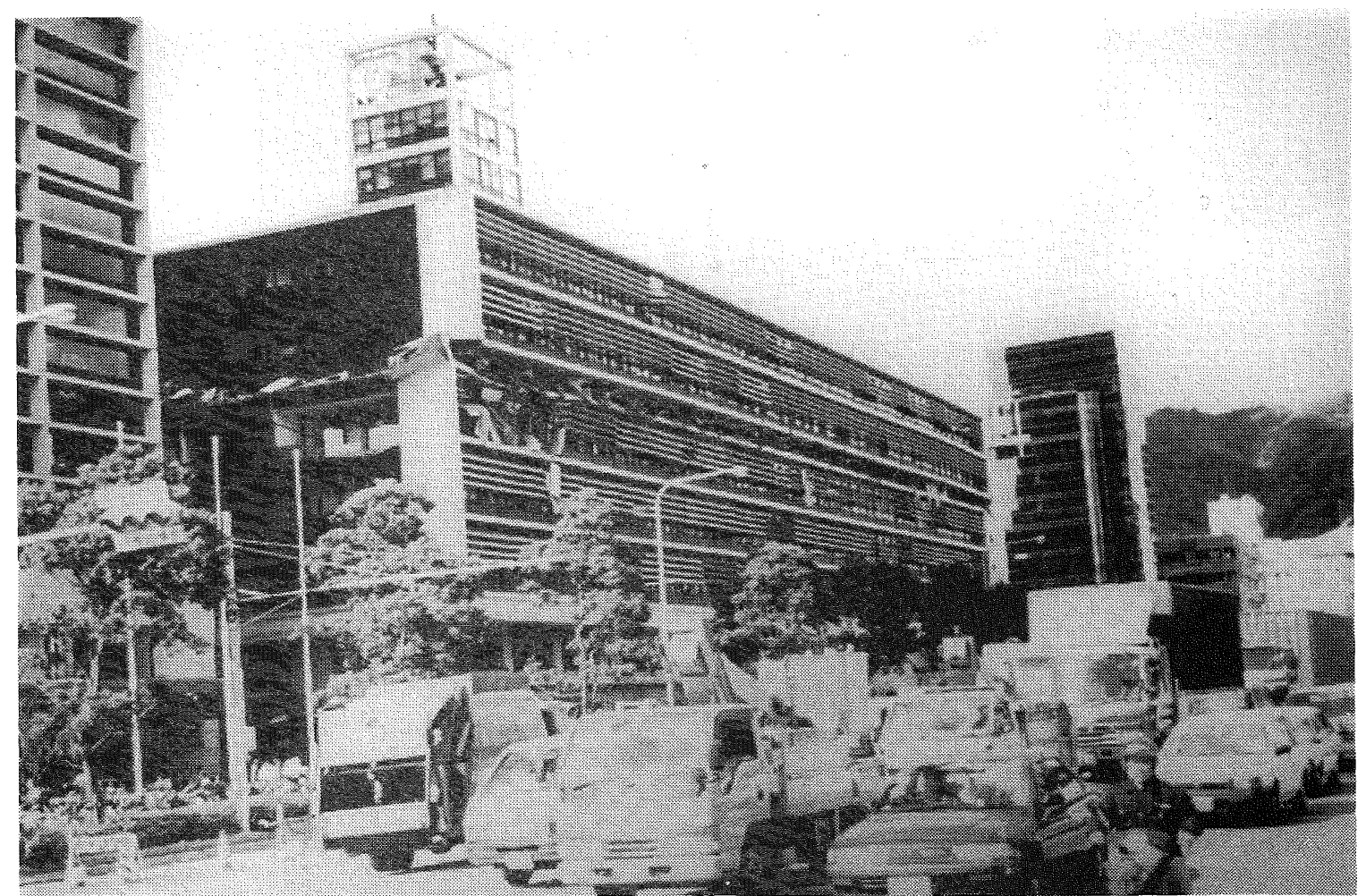

Fig. 10: Soft storey collapse of an intermediate storey of a municipal building, (Kobe, 1995).

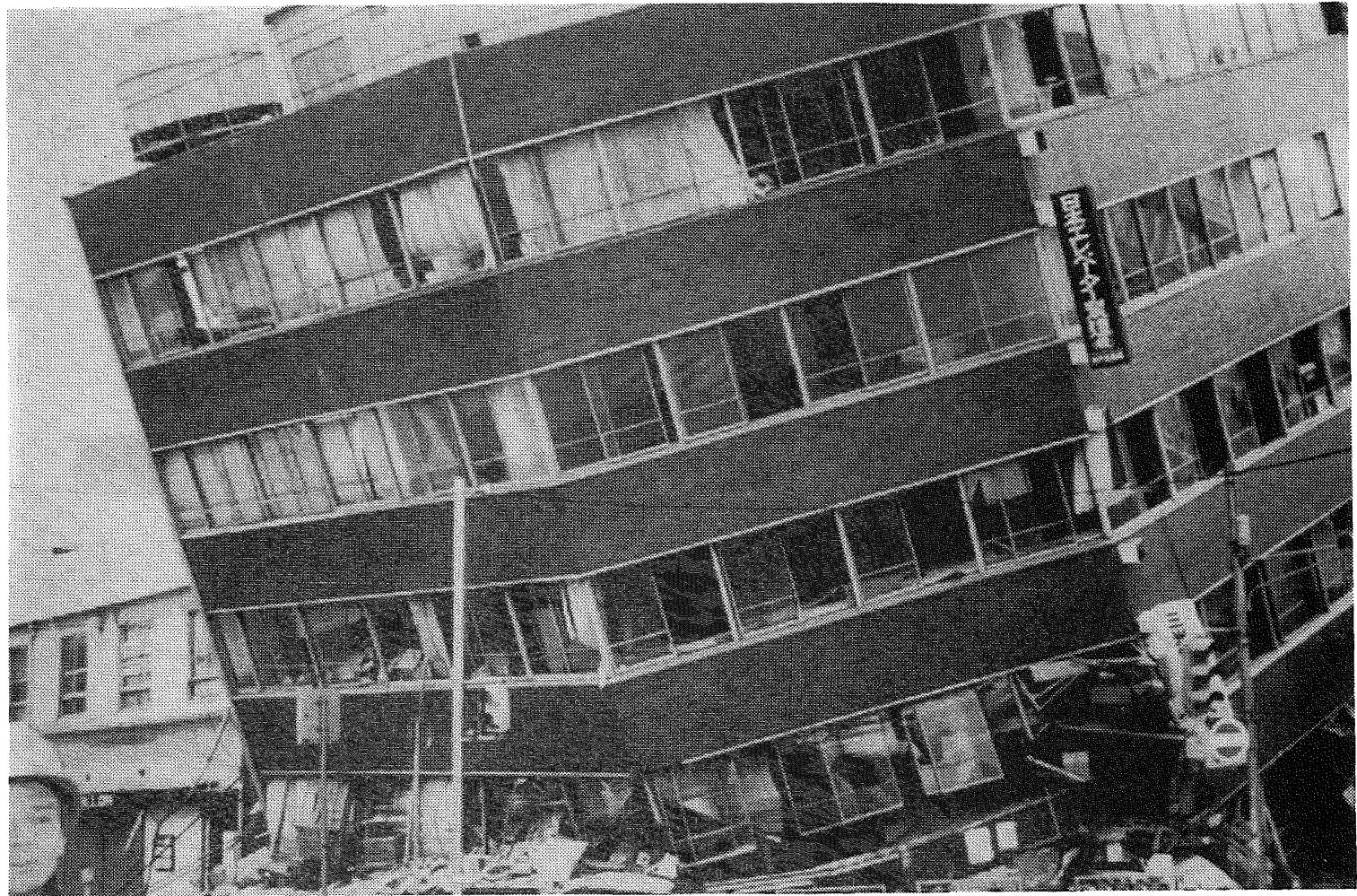

Fig. 11: Collapse of a building with an unsymmetrical structural configuration (Kobe, 1995). 


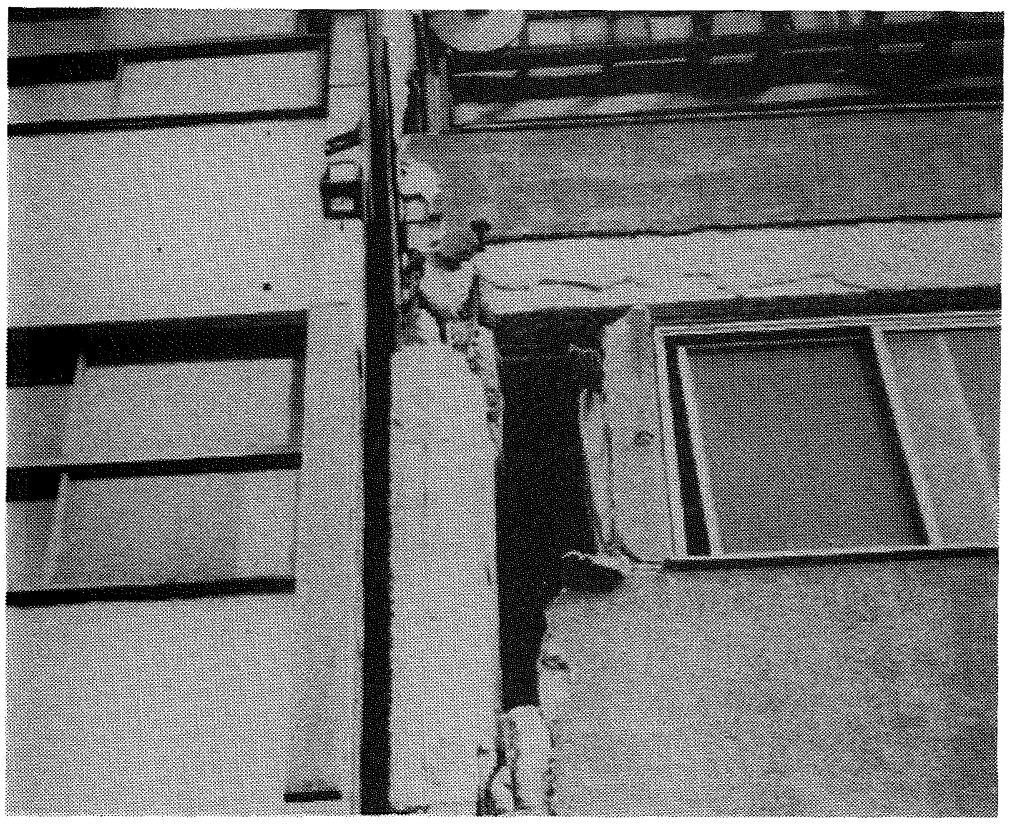

Fig. 12: Failure of reinforced concrete beam-column connection regions (Kobe, 1995).

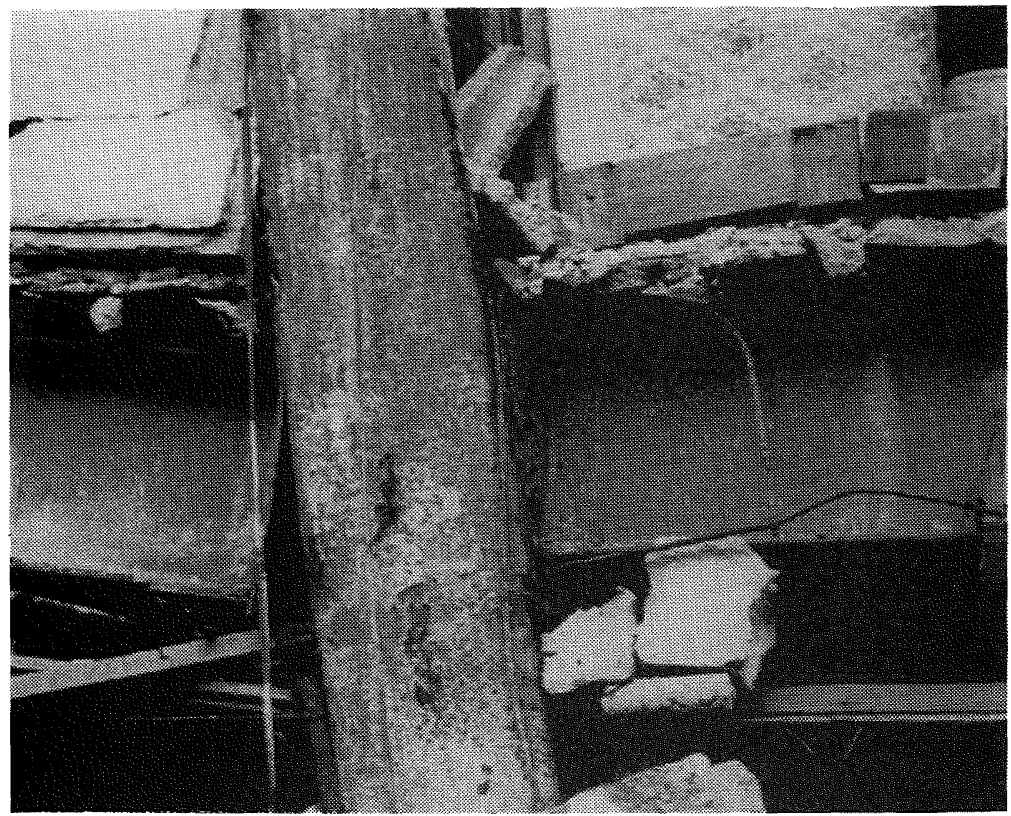

Fig. 13: Failure of a structural steel beam-column connection region (Kobe, 1995). 


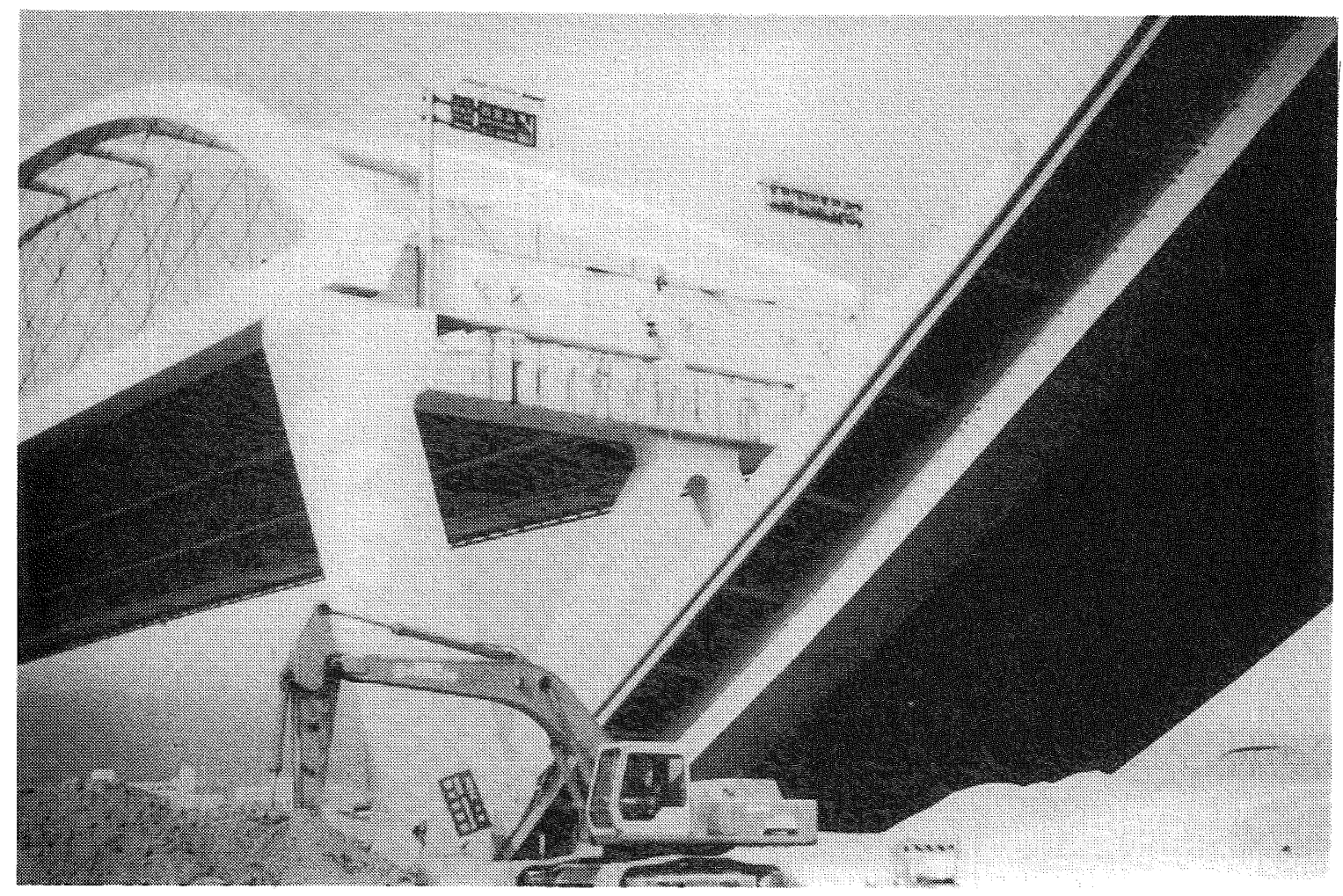

Fig. 14: Loss of approach span of the Nishinomiya-ko Bridge (Kobe, 1995).

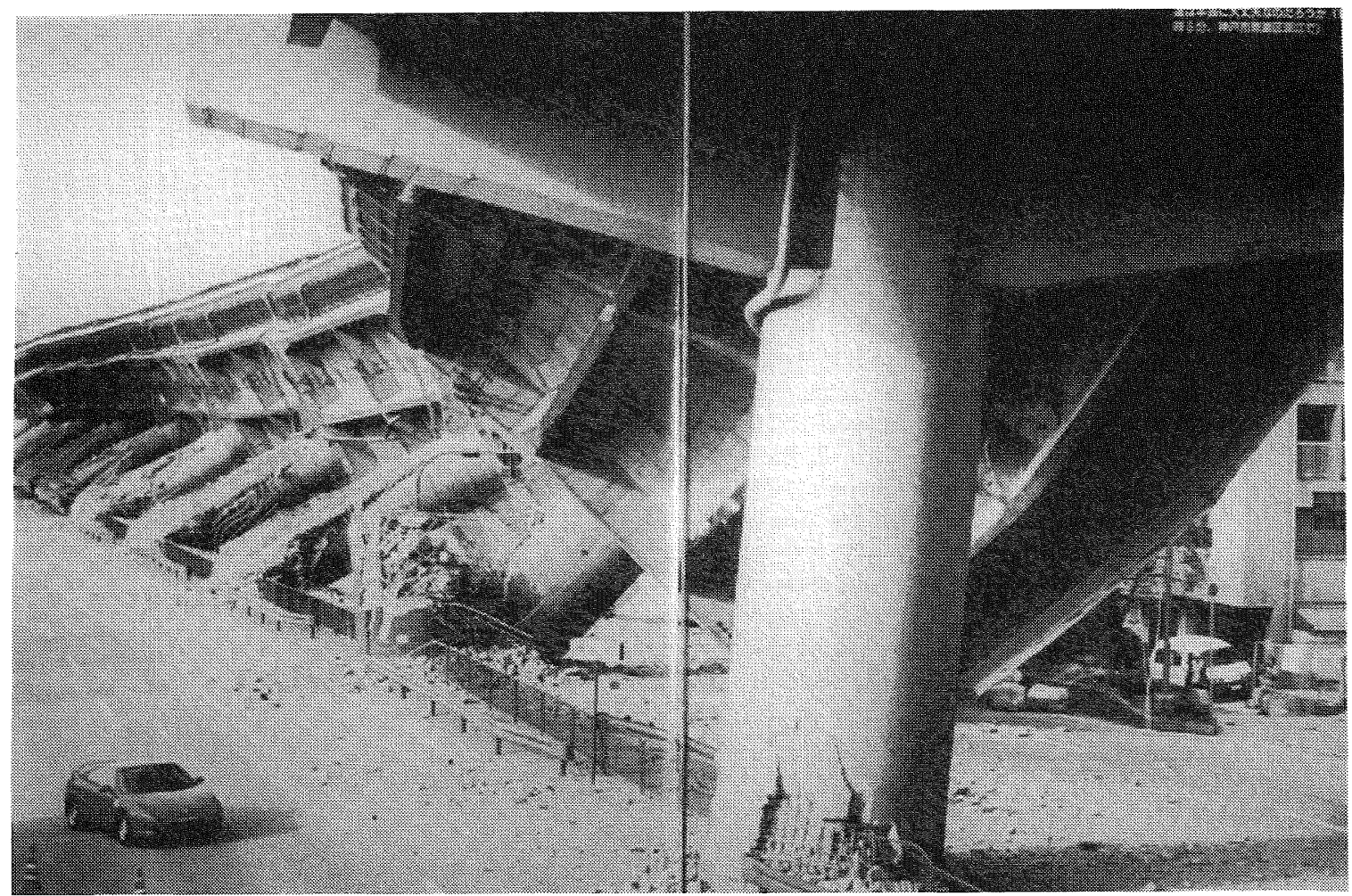

Fig. 15: Failure of columns of the Hanshin Expressway near Ashiya (Kobe, 1995). 


\section{DESIGN OF STRUCTURES FOR RESISTANCE TO EARTHQUAKES}

The ductile design approach

\subsubsection{Introduction}

Before the mid 1970s the seismic design procedures for structures in New Zealand, as in other countries of the world, were still in their infancy. It was not realized that because the seismic forces used in design were generally much smaller than the seismic forces induced in an elastically responding structure during a severe earthquake, the structure needed to possess adequate ductility to survive the earthquake. Ductility here is defined as the ability to maintain force carrying capacity while being displaced into the post-elastic range. For example, Fig. 16 shows the elastic and ductile response of a simple structure. If the structure is able to resist the horizontal inertia force $V_{c}$ corresponding to elastic response it will not need to enter the post-elastic range. However, this force $V_{c}$ in New Zealand can be as high as $1.0 \mathrm{~g}$. For many years a much smaller force $\mathrm{V}_{\mathrm{d}}$ has been used in design (for example, $0.1 \mathrm{~g}$ was recommended in the 1935 Standard Model Building By-Law). In order to survive the earthquake without collapse, when a design force $V_{d}$ which is less than $V_{e}$ is used, the structure must be able to yield in the post-elastic range in a ductile manner to horizontal displacement $\Delta_{\mathrm{u}}$.
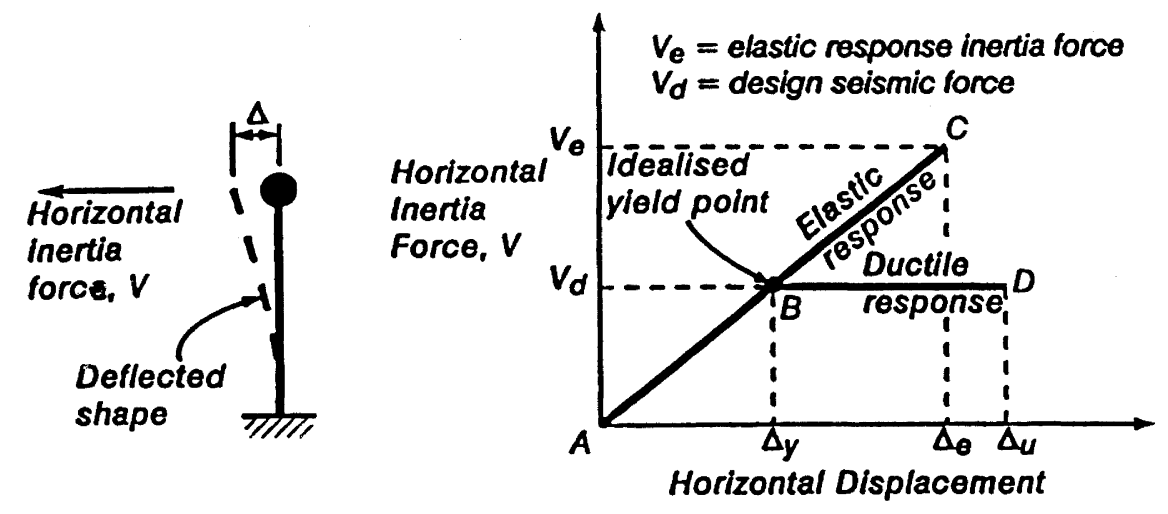

Fig. 16: Elastic and ductile response of a simple structure responding to an acceleration pulse of a severe earthquake.

In summary, the design horizontal seismic force (design acceleration $x$ mass) of the ductile structure is dependent on the available displacement ductility factor $\mu=\Delta_{\mathrm{u}} / \Delta_{\mathrm{y}}$ of the structure, which in turn is dependent on the available ductility of the plastic hinge which forms in the region of yield of the column [8]. The design horizontal seismic forces at the ultimate limit state for the design earthquake as specified by seismic codes are generally found by factoring down the accelerations found from the elastic response spectra for the design earthquake, in order to account for the reduction in the elastic response inertia forces possible due to the ductility of the structure. Figure 17 shows typical currently used design spectra for seismic loading from the 1992 New Zealand Standard for general structural design and design loadings for buildings [9]. The basic seismic coefficient for design horizontal seismic forces as a proportion of $g$ is plotted against the natural period of vibration of the structure for a range of displacement ductility factors. In design these spectra are modified to take into account the type of soil, importance of the building and the variation of seismicity throughout New Zealand.

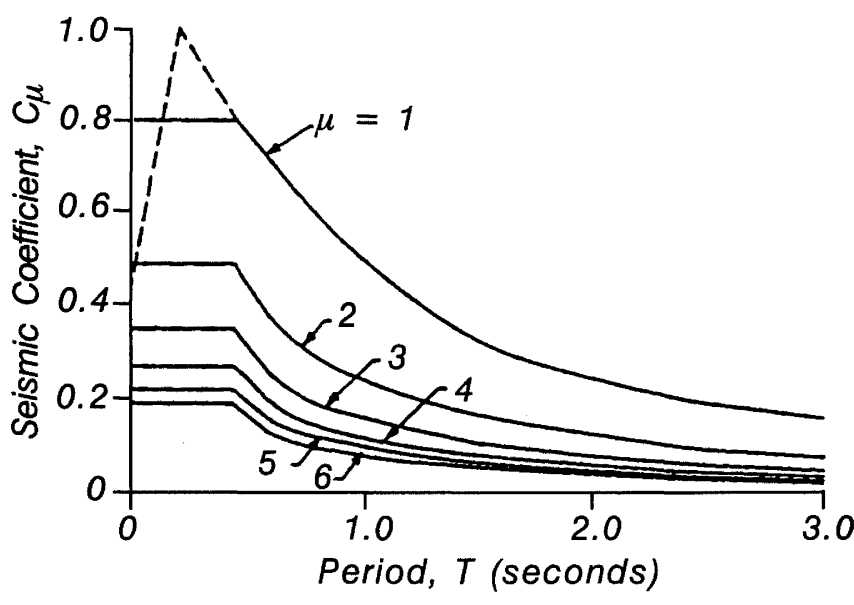

Fig. 17: Seismic hazard acceleration response spectra for intermediate soil sites [9].

The requirement that structures possess adequate ductility was first introduced in the New Zealand Standard Model Building By-Law in 1965. With regard to the level of design seismic forces the commentary to the Standard stated: "When a large recorded earthquake is applied to a building and the resultant forces calculated on the assumption that the building deforms elastically with 5 percent or 10 percent damping, very large forces are obtained. These calculated forces are 
usually several times larger than the static forces which are applied during design under existing building codes. Despite the size of the calculated forces, well constructed buildings have performed surprisingly well during past earthquakes. This reserve of earthquake resistance has been attributed to the ductility of the building - the plastic deformation of the structural components and foundations which absorb energy from the building motion. Hence, buildings in which such plastic deformation is acceptable have a considerable reserve of earthquake resistance beyond their capacity when stressed only to the elastic limit".

Hence the 1965 New Zealand Standard acknowledged the importance of ductility. However, its requirements for ductility were stated only in the following general form: "All elements within the structure which resist seismic forces or movements and the building as a whole shall be designed with consideration for adequate ductility". No guidelines were given as to how "adequate ductility" was to be achieved. The commentary to the code stated that a safeguard is to limit "the use of reinforced masonry buildings to low structures of minor importance and by building in reinforced concrete in the intermediate field and in structural steel of adequate ductility for taller structures and for those of importance to the community".

Significant advances in the seismic design of building structures have been made since the 1965 standard. These have been the outcome of a better understanding of the nonlinear dynamic response for a range of structural configurations, an awareness of the effects of the balance of strength of members on the mechanisms of post-elastic deformations of structures, and the development of methods for detailing reinforcement in reinforced concrete structures so as to achieve the ductile behaviour. Also, there has been considerable experience overseas of significant non-structural damage due to excessive displacements during earthquakes.

A large step forward was the incorporation of these advances in a new generation of seismic design standards in New Zealand, which commenced with the publication of a standard for general structural design and design loadings for buildings in 1976. The current issue of that standard is dated 1992 [9]. The field of concrete design also progressed rapidly. The pioneering concrete design standard published in 1982 was the result of a good deal of New Zealand research and development, mainly at the University of Canterbury, University of Auckland and the Ministry of Works and Development, assisted by Study Groups of the New Zealand National Society for Earthquake Engineering which gave significant input from the design profession. This standard gave detailed recommendations for methods of achieving ductile behaviour of concrete structures. The current issue is dated 1995 [10]. Similar advances have now occurred in the current design for structural steel and timber.

There is no doubt that the confidence, that designers in New Zealand have, that adequate ductility can be achieved in concrete structures of all heights has come about mainly as a result of the introduction of the capacity design approach and of the methods for the detailing of reinforcement for ductility, recommended by the current standards and described in Sections 3.1.7 and 3.1.8.
Some methods for achieving ductility in the post-elastic range for a range of structural types and materials responding to severe earthquakes are illustrated in Fig. 18. These methods involve yielding at chosen regions of the structure, selected by the designer, to achieve adequate ductility.

\subsubsection{Current Performance Criteria}

The occurrence of post-elastic strains in a structure during a severe earthquake may imply some degree of damage at the yielding regions. The performance criteria specified in the 1992 New Zealand standard for general structural design and design loadings for buildings [9] for seismic design are:

(a) Serviceability Limit State:

The structure should have sufficient stiffness and strength to be able to resist earthquakes with a return period of about 10 years without damage. That is, during such earthquakes the structure should remain essentially in the elastic range with limited interstorey deflections.

(b) Ultimate Limit State:

The structure should have sufficient stiffness, strength and ductility to be able to resist earthquakes with a return period of 450 years without:

(i) Endangering life, or

(ii) Causing loss of function to buildings dedicated to the preservation of human life, or for which the loss of function would have a severe impact on society, or which as a whole contain crowds of people, or

(iii)Causing damage to the contents of publicly owned buildings which house contents of high value to the community, or

(iv) Causing contact between parts of the building if such contact would damage the parts to the extent that persons would be endangered, or detrimentally alter the response of the structure, or reduce the strength of structural elements below the required strength, or

(v) Exceeding the building separation from site boundaries or between neighbouring buildings on the same site, or

(vi) Causing loss of structural integrity 


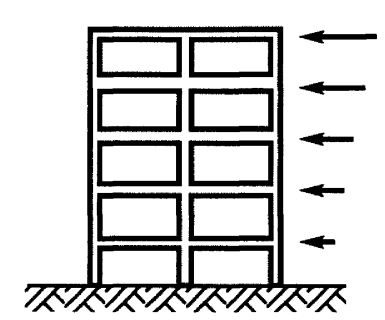

Frame

Let $n=$ No. of storeys

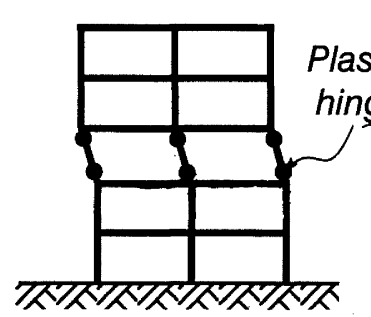

Column sidesway mechanism

Permitted only for small $n$

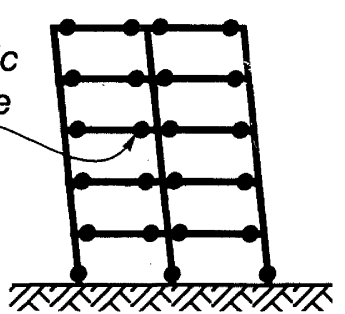

Beam sidesway mechanism

Permitted for all $n$

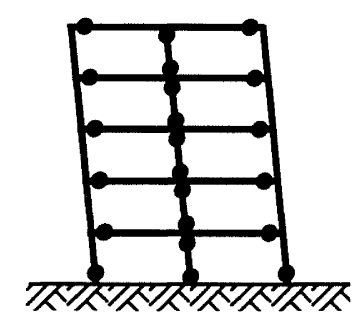

Mixed sidesway mechanism

Permitted for all $n$ but with restrictions

\section{Moment Resisting Frames of Concrete or Steel}

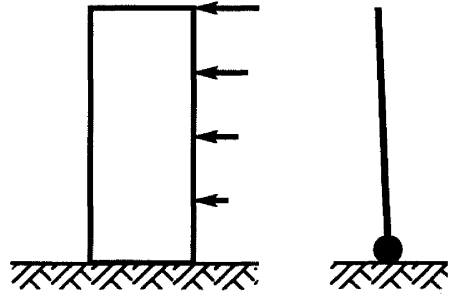

Cantilever structural walls and mechanism

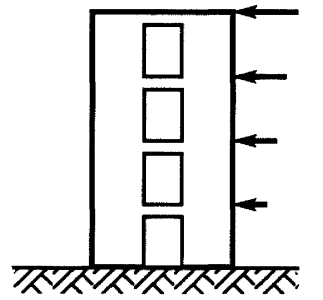

Coupled structural walls and mechanism

\section{Walls of Structural Concrete}
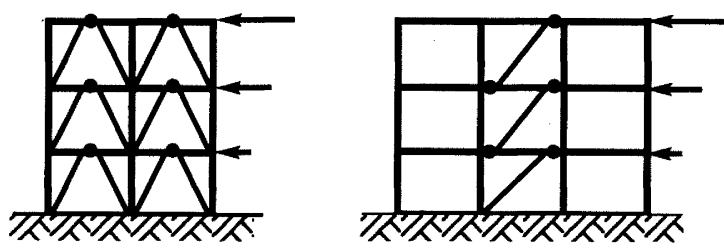

- Plastic yielding in flexure and/or shear

Eccentrically braced frames
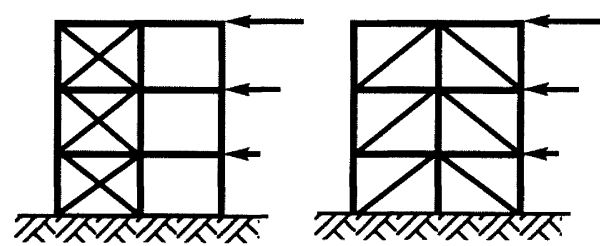

The diagonal braces yield in axial tension but may have limited load capacity in compression due to possible buckling

Concentrically braced frames

\section{Structural Steel Braced Frames}

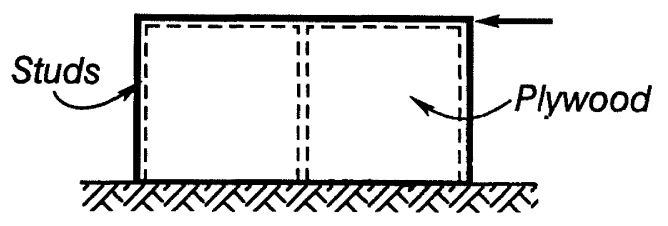

The major part of the inelastic deformation is caused by the plywood slipping over the timber studs due to nails yielding in flexure and the timber crushing locally

\section{Timber Walls with Plywood Facing}

Fig. 18: $\quad$ Some methods for achieving ductile behaviour for a range of structural types and materials responding to severe earthquakes. 


\subsubsection{Possible future performance criteria}

Current building standards recommend levels of design seismic forces for earthquakes which for a given seismic zone and period of vibration depend on the importance of the structure and the available ductility. It is likely that future design standards will give more emphasis to performancebased design. The major current performance criterion at the ultimate limit state emphasises life safety. The possible loss of function of the building due to structural and nonstructural damage after a major earthquake is given less emphasis. Yet that damage could lead to very considerable disruption of business and other activities. More performance-based criteria stipulating permissible strain and deformation levels need to be introduced into standards to ensure that the damage caused by a major earthquake is tolerable. Ideally the damage after reaching the ultimate limit state during a severe earthquake should be repairable.

\subsubsection{Structural configuration}

Experience of past earthquakes has demonstrated that buildings with a symmetrical structural configuration, both horizontally and vertically, behave much better during earthquakes than buildings with an irregular structural configuration. Hence the arrangement of the seismic force resisting elements of a building structure (frames and/or walls) should, as nearly as is practicable, be located symmetrically about the centre of mass of the building. This requirement is in order to minimise the torsional response of the building during an earthquake. Unsymmetrical structural configurations can result in significant twisting about the vertical axis of the building and hence lead to greater curvature ductility demands on some parts of the structure than for symmetrical structural configurations. It is also undesirable for significant discontinuities in stiffness and/or strength of the structural system to exist up the height of the building. For example, the absence of some vertical structural elements in one storey of a building can lead to a dangerous concentration of ductility demand (that is, a column sidesway mechanism) in the remaining elements of that storey. The 1992 New Zealand standard for general structural design and design loadings for buildings [9] gives rules for defining structural regularity.

When moment resisting frames are used as the horizontal force resisting system in buildings in New Zealand, the general trend is to design the perimeter frames with sufficient stiffness and strength to resist most of the horizontal design seismic forces [11]. The more flexible interior columns of the building then carry mainly gravity loading and can be placed with greater spacing between columns. For the perimeter frames the depth of the beams may be large without effecting the clear height between floors inside the building. Also, the columns of the perimeter frames can be at relatively close centres.

An alternative to moment resisting frames is to use structural walls to resist most of the seismic forces, or some combination of frames and walls. Properly designed structural walls in buildings have large inherent strength and their large stiffness means that displacements during severe earthquakes are reduced, thus providing a high degree of protection against damage to structural and non-structural elements [12]. The trend towards moment resisting frames, rather than structural walls, in New Zealand in recent years has been mainly due to architects preferring the more open spaces of floors when walls are not present

\subsubsection{Design seismic forces}

The New Zealand standard for general structural design and design loadings for buildings [9] and the concrete design standard [10] specify values for the displacement ductility factor :, which determine the design seismic forces and the design procedure, for the following three categories of ductility for reinforced concrete structures:

- Elastically Responding Structures : $\mu=1.25$

Structures which are expected to respond essentially in the elastic range at the ultimate limit state are exempt from special seismic design requirements providing that under seismic actions greater than assumed appropriate energy dissipating mechanisms form.

- $\quad$ Structures of Limited Ductility : $\mu \leq 3$

Structures which are expected to respond with limited ductility demand, part way between elastically responding and ductile, at the ultimate limit state are designed for that level of limited ductility.

- Ductile Structures : $\mu \leq 6$

Structures which are expected to respond in a ductile manner at the ultimate limit state are designed for that higher level of ductility.

In regions of high seismicity generally it is uneconomic to design buildings for the large seismic forces associated with response in the elastic range $(\mu=1.25)$ and $\mu$ values corresponding to structures of limited ductility or ductile design are used. However, for the design of structures in regions of medium seismicity it would be appropriate to design for : values corresponding to elastically responding structures or structures of limited ductility, since then the requirements of seismic design for ductility are not so onerous.

The effects of the seismic forces acting on a structure as a result of earthquakes are usually determined by one of the following methods:

(a) Static analysis, using equivalent static seismic forces obtained from acceleration response spectra for horizontal earthquake motions. Generally the distribution of horizontal forces up the height of the structure follows approximately the shape of an inverted triangle (see Fig. 18)

(b) Dynamic analysis, either the modal response spectrum method or the numerical integration time-history method using earthquake records.

According to the New Zealand standard for general structural design and design loadings for buildings [9], the equivalent static load method of analysis can only be used either for any structure not more than 5 storeys in height or for taller structures that satisfy the horizontal and vertical regularity requirements of the standard up to about 20 storeys in height. 
In any case the use of comprehensive computer programmes for the static and dynamic analysis of structures is commonplace in New Zealand.

\subsubsection{New Zealand requirements for post-elastic mechanisms of deformation of structures responding to severe earthquakes}

(a) Moment resisting frames of reinforced concrete and structural steel

Possible post-elastic mechanisms for moment resisting frames responding to severe earthquakes are shown in Figure 18. For tall buildings the curvature ductility required at the plastic hinges of a column sidesway mechanism may be so large that it cannot be met and in that case collapse of the structure will occur. Alternatively, if yielding commences in the beams before the columns, a beam sidesway mechanism can develop which makes more moderate demands on the curvature ductility factors required at the plastic hinges in the beams and at the column bases [8]. The curvature ductility demands at the plastic hinges of this mechanism can be met by careful detailing of reinforcement. As a result of the above considerations, New Zealand standard for general structural design and design loadings for buildings [9] requires that the columns of multistorey ductile moment resisting frames should normally have adequate flexural strength so as to ensure, as far as possible, the formation of beam sidesway mechanisms (that is, a strong column-weak beam design). Exceptions for reinforced concrete frames [10] are that column sidesway mechanisms are permitted for up to two storey ductile frames and for up to three storey frames of limited ductility, and mixed sidesway mechanisms are permitted with restrictions (see Fig. 18).

\section{(b) Structural walls of reinforced concrete}

Ductile or limited ductility behaviour of structural walls should be obtained by plastic hinge rotation as a result of flexural yielding [10]. Fig. 18 shows desirable mechanisms of post-elastic deformation of walls during severe seismic loading. For cantilever walls plastic hinging should develop at the base. For walls coupled by beams plastic hinging should also develop in the coupling beams (see Fig. 18). For the ductile or limited ductility behaviour of combined systems of moment resisting frames and structural walls the deformations of the frames will be controlled and limited by the much stiffer walls.

\section{(c) Braced frames of structural steel}

Moment resisting frames of structural steel of tall buildings may be too flexible to meet the interstorey horizontal displacement limitations. Braced frames (see Fig. 18) are more stiff and may be necessary for tall buildings. Concentrically braced frames have the possible disadvantage that the compression braces may buckle after having yielded in tension. Eccentrically braced frames where the yielding occurs over small lengths of beam in flexure and/or shear is a preferred alternative.

(d) Timber walls with plywood facing
The use of timber framing with plywood facing has excellent potential and should have a greater use for buildings in New Zealand.

\subsubsection{Capacity design approach to achieve the desired means of post-elastic deformation}

The complete characteristics of the earthquake ground shaking that may occur at a site cannot be known with certainty before an earthquake. Also, it is difficult to completely evaluate the exact behaviour of a complex structure when subjected to an earthquake.

If a structure is designed for the bending moments, axial forces and shear forces induced by earthquake actions, found by linear-elastic structural theory, the actual mode of deformation in the elastic range will be a matter of chance, depending on which critical regions reach yield first. Plastic hinges and shear failure could occur at any critical regions at random, leading to reduced available displacement ductility capacity due to column flexural failure or shear failure.

However, it is possible to design the structure in a manner that will ensure the most desirable behaviour. To ensure that the most suitable mechanism of post-elastic deformation does occur in a structure during a severe earthquake, the New Zealand design standards $[9,10]$ require that ductile structures and structures of limited ductility be the subject of capacity design. The basis of the capacity design procedure was first described in 1969 in a paper by Hollings [13] and further developed in 1975 by Park and Paulay [8]. Subsequent developments have been described in 1992 by Paulay and Priestley [14]. In the capacity design of structures, the steps are:

1. First, the appropriate regions of the primary lateral earthquake force resisting structural system are chosen and suitably designed and detailed for adequate design flexural strength and ductility during a severe earthquake.

2. Next, all other regions of the structural system, and other possible failure modes, are then provided with sufficient nominal strengths to ensure that the chosen means for achieving ductility can be maintained throughout the postelastic deformations that may occur when the overstrength flexural capacities develop at the chosen yielding regions.

It is evident that the capacity design approach according to the New Zealand concrete design standard [10] therefore requires consideration of three levels of member strength; namely: design strength $\phi S_{n}$, nominal strength $S_{n}$ and overstrength $S_{0}$.

Design strength is the nominal strength $S_{n}$ multiplied by the appropriate strength reduction factor $\phi$ where $\phi=0.85$ [10] for flexural with or without axial force or $\phi=0.75$ for shear. Nominal strength $S_{n}$ is the theoretical strength calculated using the member dimensions as detailed, the lower characteristic yield strength of the steel reinforcement and the specified concrete compressive strength.

Overstrength $S_{0}$ is the maximum likely theoretical strength calculated using the maximum likely overstrength of the steel 
reinforcement (taken to be 1.25 times the lower characteristic yield strength in New Zealand [10]), the increased concrete strength due to confinement, and reinforcement area including any additional reinforcement placed for construction and otherwise unaccounted for in calculations.

For example, for one-ways frames of limited ductility the design column bending moments are taken as $1.1 \phi_{0}, \mathrm{M}_{\mathrm{E}}$ where $\phi_{0}=$ ratio of overstrength moment capacity of the beams to the design bending moment (taken to be at least

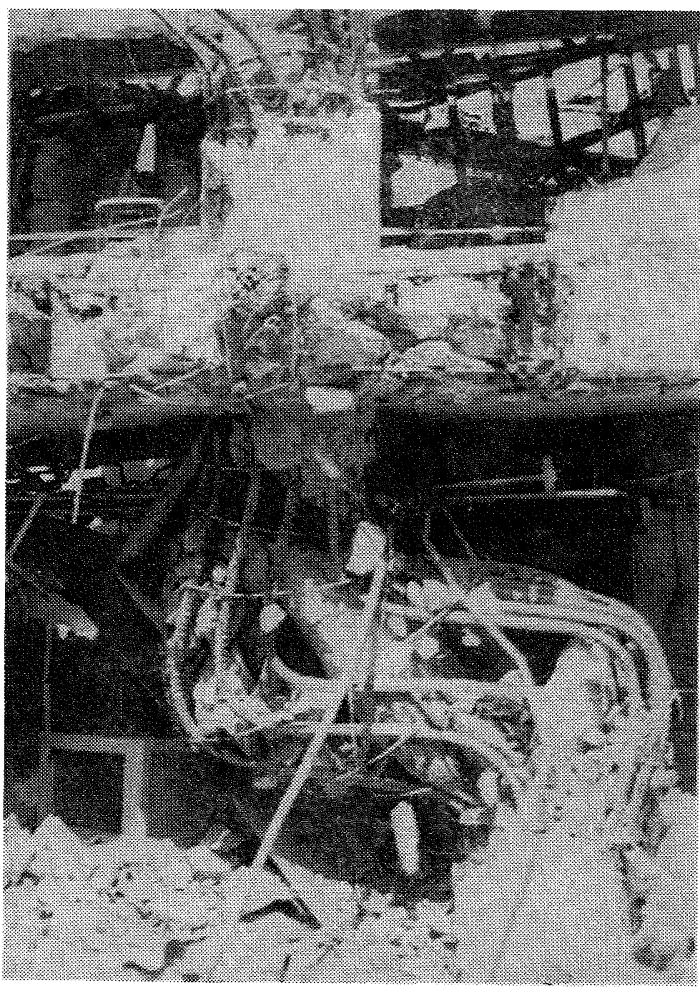

$1.25 / 0.85=1.47$ in New Zealand [10]) and $\mathrm{M}_{\mathrm{E}}=$ column moment found from elastic structural analysis for the static design earthquake forces. The 1.1 factor is to account for the higher mode effects of dynamic response. For ductile oneway frames the 1.1 factor becomes 1.3 to 1.8 , depending on the natural period of vibration of the frame. The design shear forces in beams are those associated with the overstrength flexural capacities of the beam plastic hinges [10].

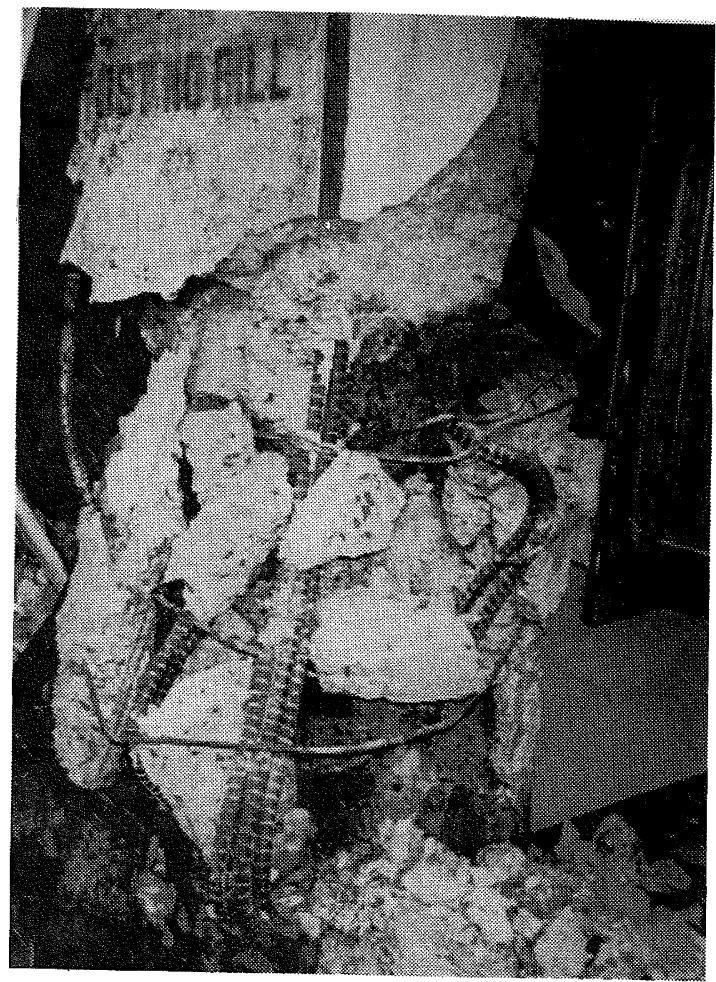

Fig. 19: Examples of brittle behaviour of reinforced concrete columns due to inadequate transverse reinforcement.

\subsubsection{Detailing of reinforcement for ductility}

A further major step forward since the 1960's has also been the development of methods for detailing reinforced concrete elements and assemblages of members for adequate ductility $[11,12,14,15,16,17]$. Poor detailing which leads to brittle failures is to be avoided. Examples or poor detailing are inadequate anchorage of longitudinal reinforcement, inadequate anchorage of transverse reinforcement, and inadequate quantities of transverse reinforcement. Inadequate anchorage of longitudinal reinforcement will result in the yield strength of the reinforcement not being developed during the cyclic loading caused by earthquakes. Lap splices may fail if placed in potential plastic hinge regions. Transverse reinforcement will not be effective if not properly anchored and/or of insufficient quantity. End hooks should preferably be bent through at least $135^{\circ} .90^{\circ}$ end hooks are definitely inadequate for perimeter hoops, since spalling of cover concrete will result in loss of anchorage. $90^{\circ}$ end hooks could be tolerated in limited ductility design when used for interior legs of hoops or ties which pass through the core concrete and are bent around intermediate column bars. Anchorage failure and/or inadequate quantities of transverse reinforcement will result in a reduction in the flexural ductility of members due to lack of concrete confinement and a lack of restraint against buckling of longitudinal bars and/or shear failure due to lack of adequate shear reinforcement (see Fig. 19). 


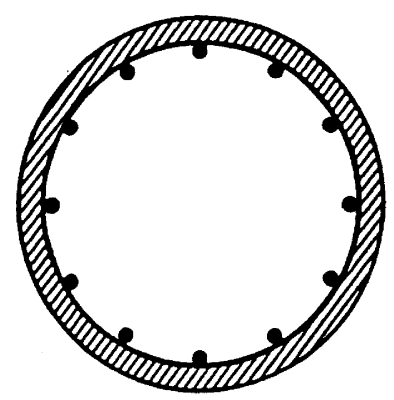

(a) Circular hoops or spiral

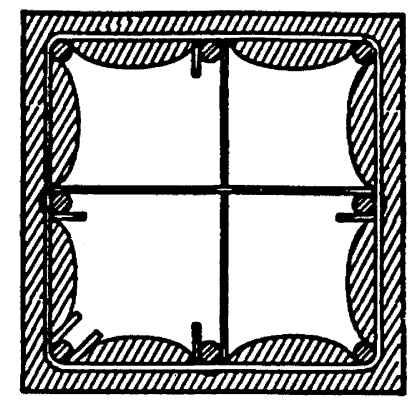

(b) Rectangular hoops with cross ties

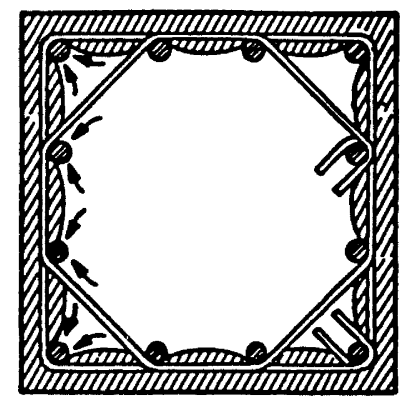

(c) Overlapping rectangular hoops

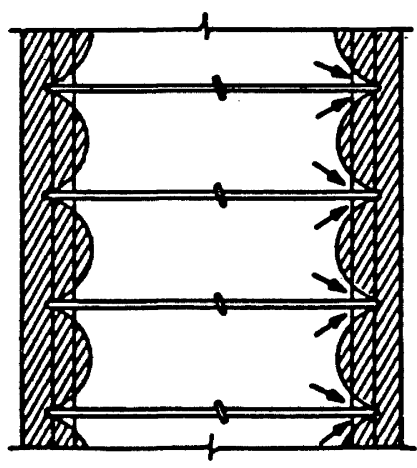

(d) Confinement by

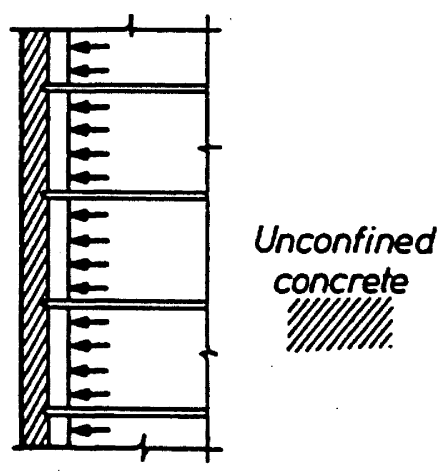

(e) Confinement by longitudinal bors

Fig. 20: Arrangements of reinforcement which confine the concrete and prevent premature buckling of longitudinal reinforcement of columns.

Consideration of the proper detailing of reinforcement is an extremely important aspect of the design for ductile behaviour. The most important design consideration for ensuring ductile plastic hinge regions of reinforced concrete beams and columns of moment resisting frames is the provision of adequate longitudinal compression reinforcement as well as tension reinforcement, and the provision of adequate transverse reinforcement in the form of rectangular stirrups, or rectangular hoops with or without cross ties, or spirals (see Fig. 20). This transverse reinforcement is needed to act as shear reinforcement, to prevent premature buckling of the compressed longitudinal reinforcement and to confine the compressed concrete. The concrete becomes confined when at stresses approaching the uniaxial compressive strength the transverse strains become very high and the concrete bears out against the transverse reinforcement. The strength and ductility of compressed concrete is greatly increased by confinement.

Also, the shear resistance of beam-column joint cores need special attention, as does the anchorage of transverse and longitudinal bars in the joint core. Figure 21 shows the forces from beams and columns acting on an interior beamcolumn joint, the crack pattern and the mechanisms which transfer the forces across the joint. Both transverse and vertical reinforcement is required across the joint to transfer the bond forces after diagonal tension cracking, and the longitudinal bars need to have adequate anchorage within the joint core to prevent bond degradation.

A great deal of research has been carried out at the University of Canterbury on methods for detailing reinforcement in beams, columns, beam-column joints and walls for adequate strength and ductility. These methods have been included in the New Zealand standard for concrete design [10], which has become widely known and referred to overseas.

Design standards do not generally expect designers to calculate the curvature ductility factors required at the plastic hinge regions of structures. The New Zealand concrete design standard [10] specifies design procedures and provisions for detailing the plastic hinge regions of the structure which are aimed at achieving adequate ductility for each of the three categories of ductility $(\mu=1.25, \leq 3$ or $\leq 6)$ and the expected mode of post-elastic deformation of the frame. Simple detailing procedures can be recommended for elastically responding structures $(\mu=1.25)$ and structures of limited ductility $(\mu \leq 3)$.

For example, for the design of ductile moment resisting frames [10]:

(a) In the potential plastic hinge regions at the ends of beams the horizontal centre to centre spacing of the 
stirrup-ties should not exceed the smaller of onequarter of the effective depth of the beam or 6 times the diameter of the longitudinal bars. Methods are given for calculating the area of transverse reinforcement required for the prevention of shear failure and to restrain buckling of longitudinal bars.

(b) In the potential plastic hinge regions at the ends of columns the vertical centre to centre spacing of hoops or spirals should not exceed the smaller of one-quarter of the least lateral dimension of the column cross section or 6 times the diameter of the longitudinal bars. Methods are given for calculating the area of transverse reinforcement required for the prevention of shear failure, to confine the concrete and to restrain buckling of longitudinal bars.

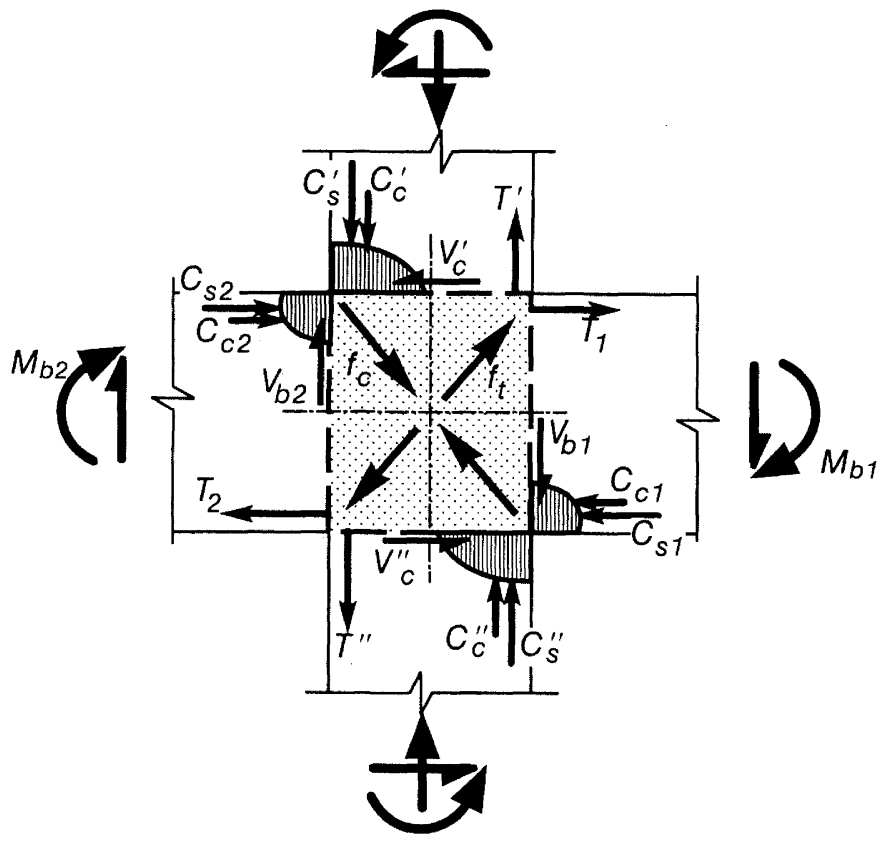

(a) Forces from beams and columns acting on the joint

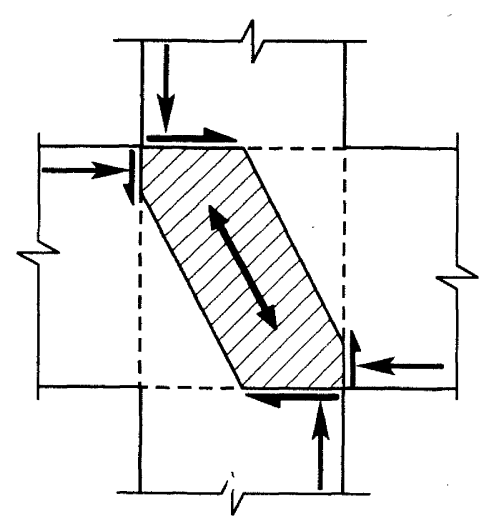

(c) Concrete diagonal strut mechanism, equlibrating concrete compression forces in beams and columns and some bond forces in the compression zones
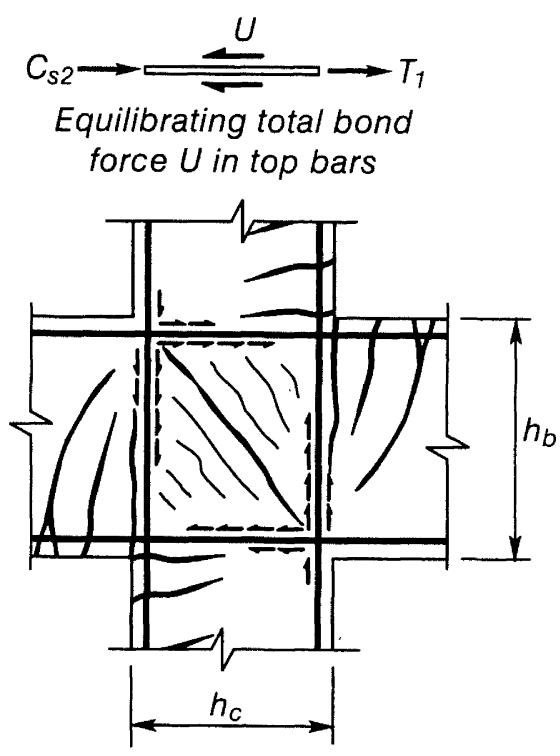

(b) Crack pattern and bond forces after diagonal tension cracking initiates in joint core

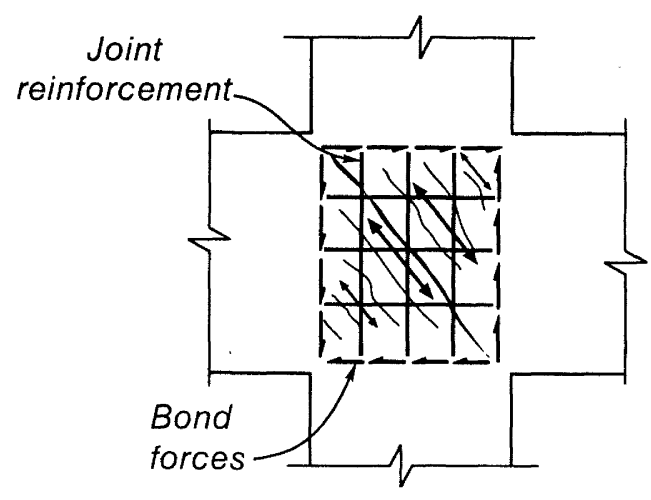

(d) Truss mechanism of concrete diagonal compression field and horizontal and vertical reinforcement needed for equilibrium after diagonal tension cracking

Fig. 21: Forces acting on an interior beam-column joint during an earthquake and the resulting cracking and mechanisms of force transfer. 


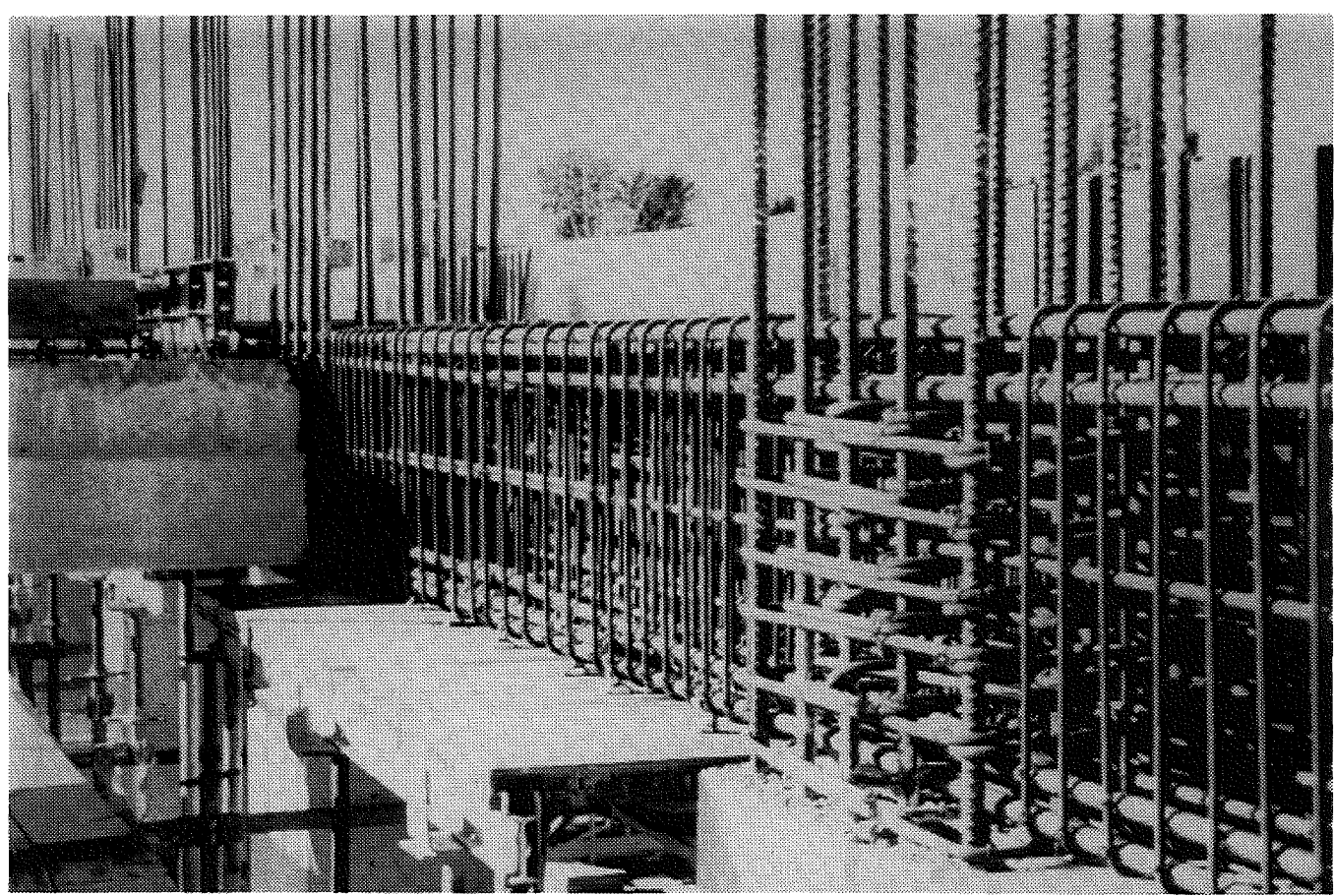

(a) Beam

(c) Beam-Column Joint

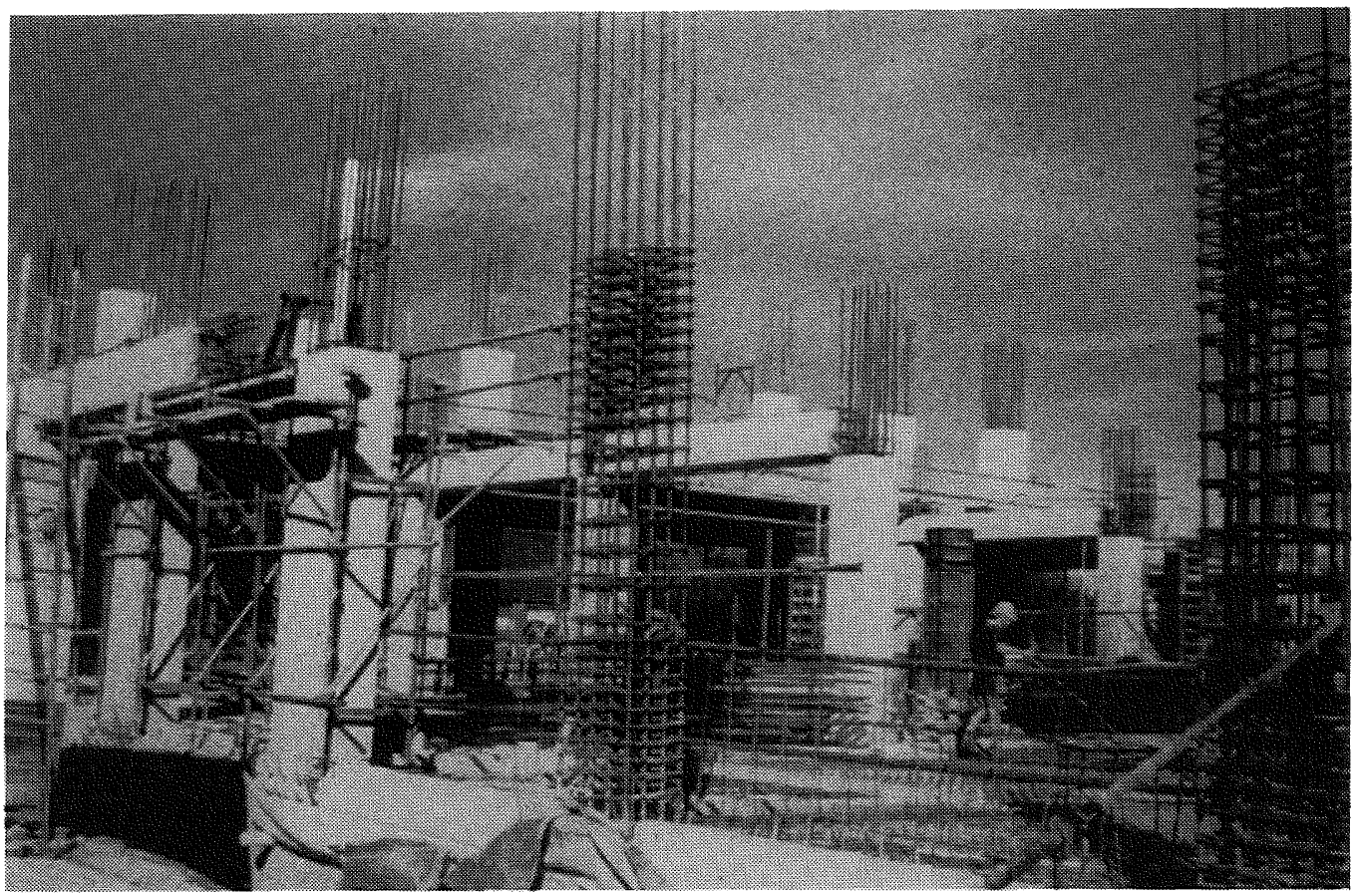

(c) Columns

Fig. 22: Typical reinforcement for ductile moment resisting frames in New Zealand. 
(c) In beam-column joints methods are given for calculating the horizontal and vertical reinforcement required to avoid shear failure and also the diameter of longitudinal bars passing through the joint to avoid bond failure.

Figure 22 shows typical reinforcement for ductile moment resisting frames in New Zealand.

\subsubsection{Control of interstorey displacements}

The New Zealand Standard for general structural design and design loadings for buildings [9] recommends that when the equivalent static force method or the modal response spectrum method is used, the interstorey drift (defined as the interstorey horizontal displacement divided by storey height) at the ultimate limit state should not exceed either 1.5 or $2.0 \%$, depending on the height of the building. The purpose of the limit on interstorey displacements of the structure is so that those displacements do not endanger life, or cause of loss of function of important or crowded buildings, or cause damage to high value contents, or cause inappropriate damage to non-structural elements, or exceed building separation, or cause loss of structural integrity.

\subsubsection{A future trend in design approach}

The current seismic design approach is to design the structure for adequate strength and ductility for the design seismic forces and then to check that the resulting interstorey displacements are satisfactory. This is known as force based design. However, a structure's ability to survive earthquakes is more a matter of its displacement capacity than its initial yield strength. It has been suggested for example [18] that the initial input into the design process should be the desired seismic displacement rather than the seismic forces. This latter approach is referred to as displacement-based design and currently being developed in many countries. Performance limit states can also conveniently be part of that design process.

\subsubsection{Summary of seismic design principles for buildings}

In summary, good seismic design of buildings involves consideration of the following aspects:

- Structural configuration - the arrangements of structural members should be symmetrical and regular as far as possible, both vertically and horizontally.

- Appropriate mechanisms of post-elastic deformation the relative strengths of modes of failure and members should be such as to ensure a desirable modes of postelastic deformation of the structure during earthquakes.

- Adequate ductility - the reinforcement should be detailed so as to ensure adequate ductility in the yielding regions during earthquakes.

- Displacement control - the interstorey drift during earthquakes should not lead to excessive damage or loss of integrity of the structure.

\subsubsection{Ductile design of bridge piers}

In New Zealand the design of highway bridges on public roads is conducted using a Bridge Manual prescribed by Transit New Zealand [19]. The seismic design loadings for bridges in the Bridge Manual are those recommended by the loadings standard of Standards New Zealand [9] for buildings modified appropriately to apply to bridges. The concrete design is conducted in accordance with the concrete design standard of Standards New Zealand [10].

\section{Potential plastic hinge zones above ground level or above normal water level.}
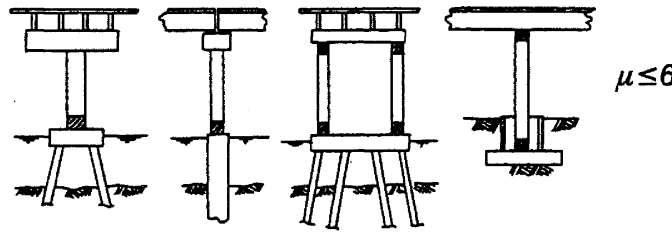

Potential plastic hinge zones less than $2 m$ below ground level but not below normal water level.
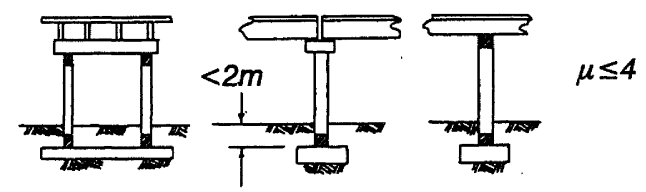

Footings designed to rock or potential plastic hinge zones more than $2 m$ below ground level or below normal water level.

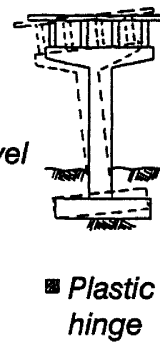

Plastic hinge zones in raked piles
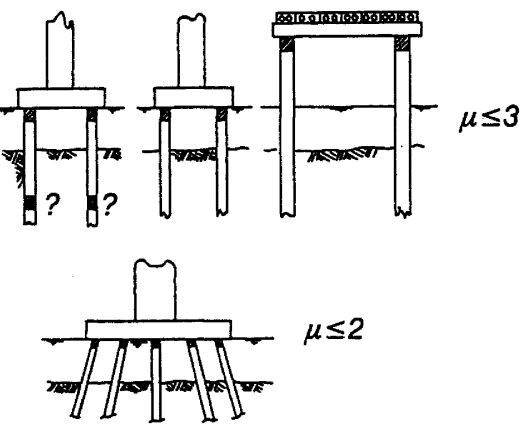

Fig. 23: Examples of maximum values of the displacement ductility factor $\mu$ permitted by the Bridge Manual of Transit New Zealand [19]. 
In the ductile design approach seismic design actions at the ultimate limit state for the design earthquake are obtained from the response spectrum appropriate to the site, the displacement ductility factor appropriate to the bridge substructure and the importance of the bridge (see Fig. 23). Capacity design is used to ensure that most desirable energy dissipating mechanism forms in the substructure in the event of a severe earthquake. Members are detailed to ensure that the required ductility is available and that the bridge structure behaves as intended $[19,20]$. For single or multiple column substructures the plastic hinges of the energy dissipating mechanism should preferably form in the columns rather than in the foundations (footings or pile caps or piles), because of the greater accessibility for inspection and repair of the columns.

Horizontal linkages between span and support, and adequate seating lengths of girders on supports, are also provided so that the bridge superstructure will not become dislodged during a major earthquake when significant displacements of the bridge substructure occurs.
3.2 Design of buildings and bridges using base isolation and mechanical energy dissipating devices

\subsubsection{Introduction}

An alternative to the conventional ductile seismic design approach is to use a base isolation design approach based on two concepts: (1). The structure is supported on flexible bearings, usually elastomeric rubber bearings, so that the period of vibration of the combined structure and supporting system is sufficiently long that the structure is isolated from the predominant earthquake ground motion frequencies, and (2). in additional, sufficient extra damping is introduced into the system by mechanical energy dissipating devices to reduce the response of the structure to the earthquake and to keep the deflections of the more flexible system within acceptable limits.

For example, Figure 24 shows a typical elastic response spectra for horizontal acceleration used in seismic design. If the natural period of vibration of the structure is increased from 0.3 seconds to about 2.0 seconds, the horizontal acceleration is reduced by about $70 \%$. Increasing the damping further reduces the acceleration.

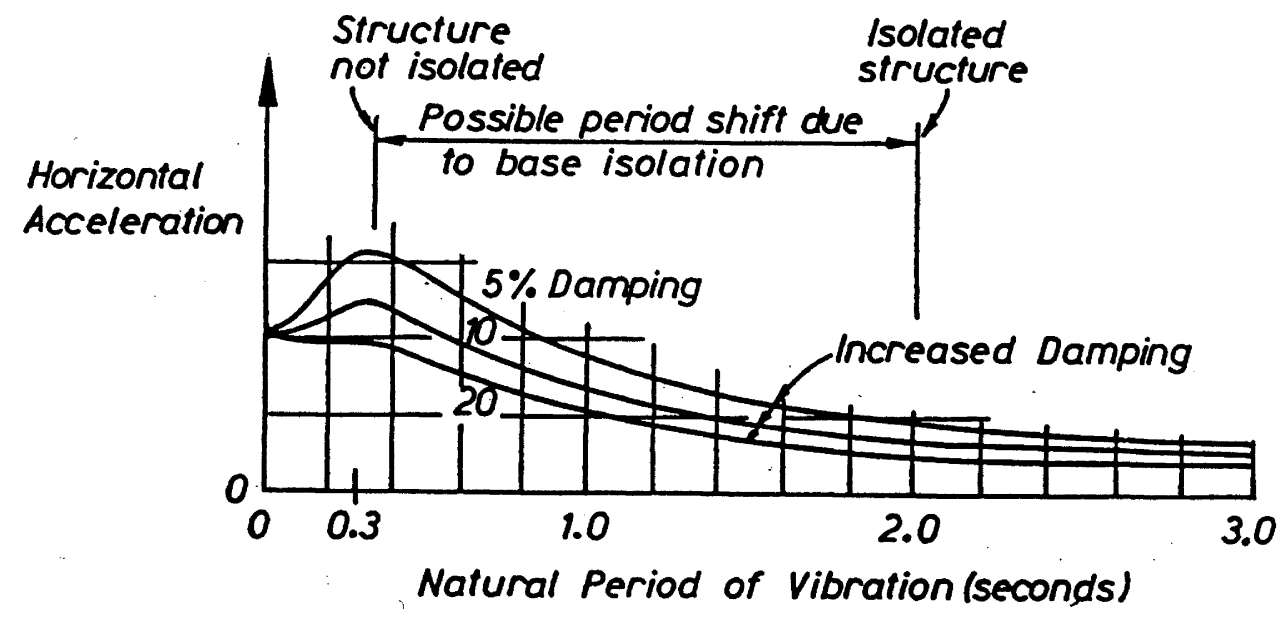

Fig. 24: Typical design elastic response spectra illustrating effect of increased period of vibration and damping.

The main flexible base isolation device used in New Zealand for buildings and bridges is an elastomeric bearing (rubber with steel sandwich plates). Commonly a lead plug is present as in the lead-rubber device shown in Figure 25. Alternatively, a flexible pile system has been used for buildings.

A range of mechanical devices which act as hysteretic dampers have been devised and investigated at the Physics and Engineering Laboratory of the Department of Scientific and Industrial Research, New Zealand [21, 22]. These energy dissipation devices may take the form of steel elements which bend or twist, lead extrusion or lead shear devices. Figure 25 shows a range of possible energy dissipating devices which have been developed. Some of these devices are suitable for insertion between the foundations and the structure of buildings or the supporting structure and deck structure of bridges. The mechanical energy dissipating devices result in a decrease in the seismic forces in the structure during a severe earthquake and hence the strength and/or ductility requirements are reduced. 


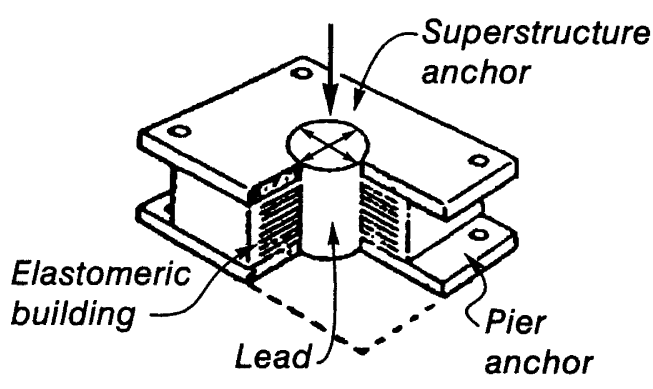

Lead-Rubber Device

Flexural beam

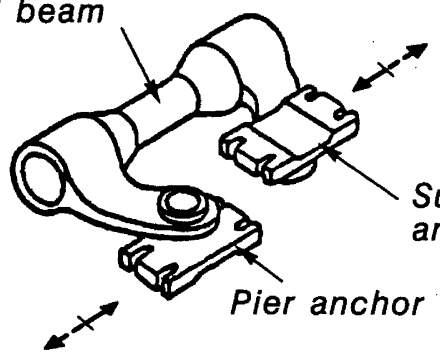

Steel Flexural Beam Device

\section{Superstructure}

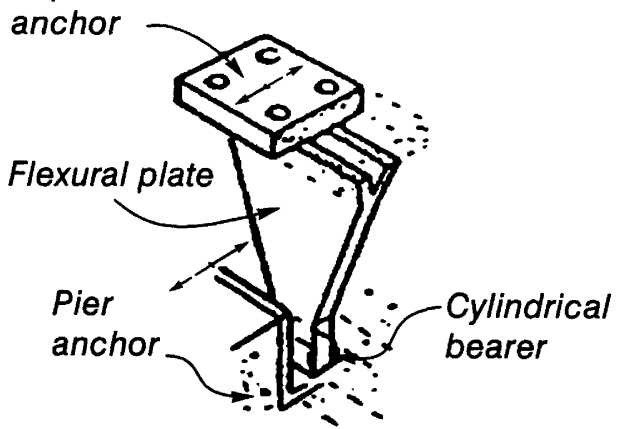

Steel Flexural Plate Device
Superstructure anchor

\section{Pier anchor}

\section{Superstructure}

anchor

Steel Flexural Beam Device

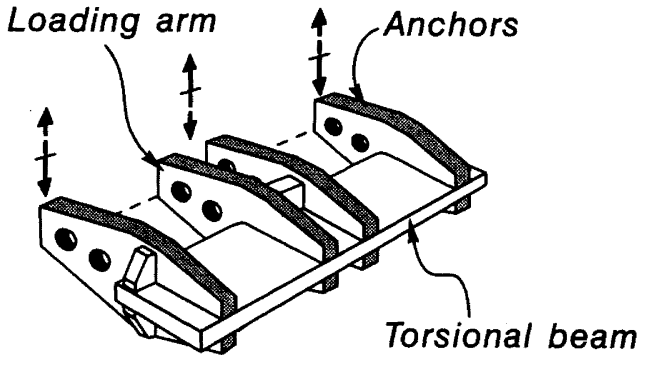

Steel Torsional Beam Device

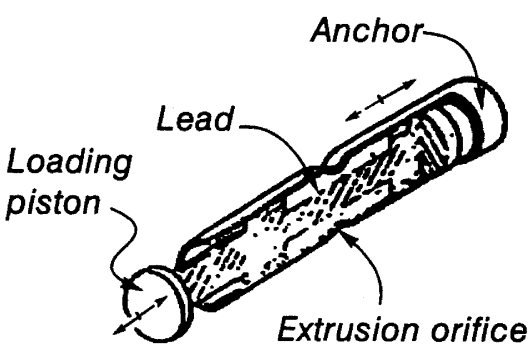

Lead Extrusion Device

Fig. 25: Mechanical energy dissipating devices [21].

Nonlinear dynamic analysis is generally necessary in the design process of base isolated structures. Studies using nonlinear dynamic analyses have demonstrated that base isolation is most efficiently employed in structures with short to intermediate natural periods of vibration. The main potential for economic advantage is in the reduction of the ductile detailing required in the structure and the greater damage control. However, it is important that consideration be given to the characteristics of the likely earthquake ground motions at the site of the structure. If the predominant frequencies of the ground motions are likely to be in the long period range, for example where the structure is sited on deep flexible alluvium, a flexible mounting system may detrimentally effect the response of the structure and would be unsuitable for use in that design.

In any case structures incorporating energy dissipating devices should be designed to deform in a controlled manner in the event of the occurrence of an earthquake greater than the design earthquake. Hence detailing procedures for the structure suitable for structures of limited ductility should be used. Separation details should allow for the possible occurrence of horizontal displacements larger than those calculated in the design earthquake. 


\subsubsection{Application to buildings}

Three examples of the use of base isolation techniques for buildings in New Zealand are given below:

\section{William Clayton Building, Wellington}

The William Clayton Building in Wellington was completed in 1982 and was the first building to be base isolated on lead rubber bearings [23]. The building has plan dimensions of 97 $\mathrm{m} \mathrm{x} 40 \mathrm{~m}$ and the cast-in-place reinforced concrete frame is four storeys in height (see Figs. 26 and b). The building is mounted on 80 lead-rubber bearings placed under the basement floor slab below each column. Each bearing is a $600 \mathrm{~mm}$ square by $207 \mathrm{~mm}$ deep elastomeric bearing with a central $105 \mathrm{~mm}$ diameter lead plug (see Fig. 26c). The lead plug was designed to yield plastically at a lateral force of about $7 \%$ of the vertical load. Nonlinear time-history dynamic analyses, using 1.5 times the $1940 \mathrm{~N}-\mathrm{S}$ El Centro earthquake record, showed that the natural period of vibration increased from 0.3 seconds for the structure without base isolation to about 2 seconds for the structure with base isolation after the lead had yielded. The maximum lateral deformation due to bearing deformation was found to be about $150 \mathrm{~mm}$.

\section{Union House, Auckland}

Union House in Auckland was completed in 1983 [24]. The building is 12 storeys in height and has the elevation shown in Figure 27. The perimeter frames are cross-braced. The 16 columns of the building are supported on piles, which are 10$13 \mathrm{~m}$ long and pass through hydraulic fill to bear on sandstone. The $900 \mathrm{~mm}$ diameter piles are pinned at both ends and are separated from the surrounding ground by being placed in $1200 \mathrm{~mm}$ diameter steel tube casings. At ground level the base of each column of the perimeter frame is attached to a tapered steel cantilever, formed of $75 \mathrm{~mm}$ thick plate. The fixed end of the tapered steel cantilevers is attached to a concrete support beam which is fixed to the ground. The base isolation systems therefore consists of flexible piles connected to mechanical energy dissipating devices at ground level. Time history analysis, using the $1940 \mathrm{~N}-\mathrm{S}$ El Centro earthquake record, indicated a maximum lateral deflection at the pile tops of about $150 \mathrm{~mm}$. The natural period of vibration of the isolated structure was about 2 seconds after yielding of the tapered steel cantilevers. The tapered steel cantilevers were chosen for energy dissipators because of their simplicity and ease of replacement. The base isolation of this building led to simpler structural details, since a ductile performance of the structure was not required. No special separation was required for nonstructural elements as the interstorey drifts were very small.

\section{Wellington Central Police Station}

The Wellington Central Police Station was completed in 1991. The building is 10 storeys in height. The building is supported by $16 \mathrm{~m}$ long piles in oversize steel casings. The basement structure is not isolated and is supported on conventional piles. On each side of the building there are six lead extrusion dampers positioned between the pile tops and the basement.
Other examples are the Museum of New Zealand Te Papa and the Hutt Valley Hospital.

\subsubsection{Application to bridges}

The first bridge to be seismically isolated in New Zealand was the Motu bridge in 1973, the superstructure of which was mounted on elastomeric bearings and steel flexural devices were used to dissipate the energy.

The application of seismic isolation to bridges in New Zealand is now commonplace.

Up to 1995 a total of 50 road and rail bridges had been seismically isolated in New Zealand. The systems used were 40 bridges with lead-rubber bearings, 1 with lead-rubber bearings plus lead extrusion dampers, 2 with rubber bearings and lead extension dampers, and 7 with rubber bearings and flexural steel devices as dampers (see Fig. 28).

\section{PRECAST CONCRETE IN BUILDINGS}

\section{$4.1 \quad$ General}

A unique aspect of New Zealand building construction is that a good deal of precast concrete is used. Currently in New Zealand almost all floors, most moment resisting frames and many one to four storey walls in buildings are constructed incorporating precast concrete elements [25]. This has come about because the use of precast concrete elements has the advantages of high quality control, a reduction in site formwork and site labour, and increased speed of construction. In particular, with high interest rates and pressure for new building space in the mid 1980's, the advantage of speed gave precast concrete frames a distinct cost advantage. Contractors have adapted to precast concrete construction with increased cranage and construction techniques and on-and off-site fabrication $[25,26]$.

This considerable use of precast concrete in New Zealand has been a significant challenge to designers, precasters and contractors because of the need for structures to have earthquake resistance. The increase in the use of precast concrete in the 1980's required a great deal of innovation. The New Zealand standard for concrete design that was current in the 1980's, like the concrete codes of many countries, contained comprehensive provisions for the seismic design of cast-in-place concrete structures but did not have seismic provisions covering all aspects of precast concrete structures. The New Zealand standard for concrete design issued in 1995 [10] contains more recommendations for precast concrete based on research and development in New Zealand.

\subsection{Precast concrete floors}

As in common in many countries, floors in New Zealand buildings in the early years were mainly of cast-in-place reinforced concrete construction. Significant use of posttensioning was also made in cast-in-place concrete floors in the 1950's and 1960's. However, since the 1960's precast concrete units, spanning one-way between beams or walls, have become widely used in floors in New Zealand. 


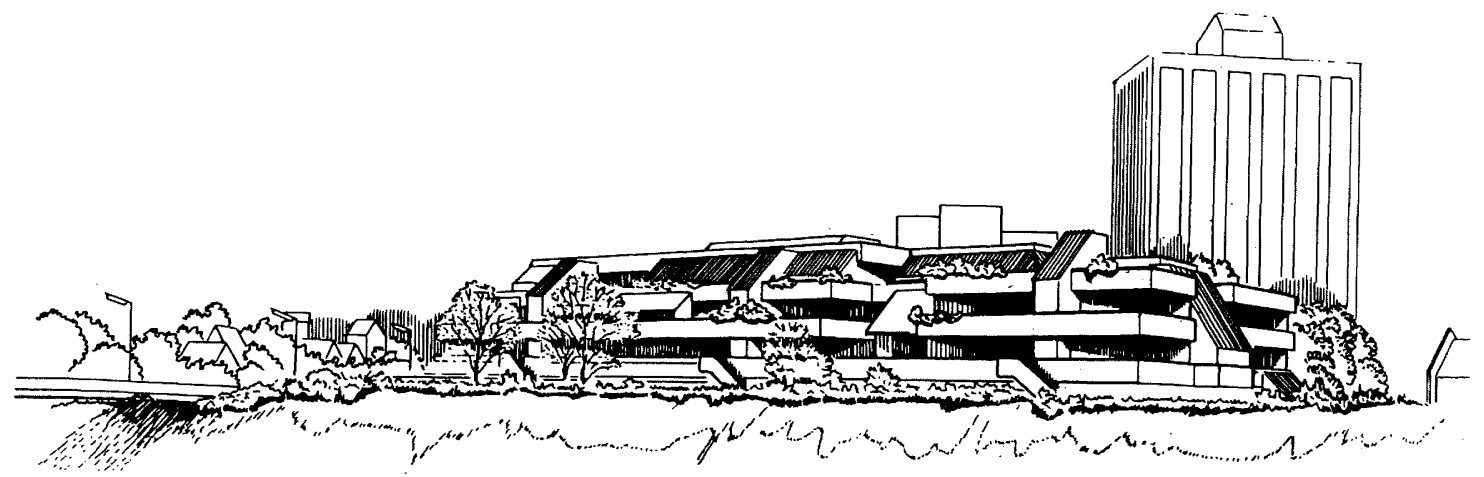

(a) Perspective of the building.

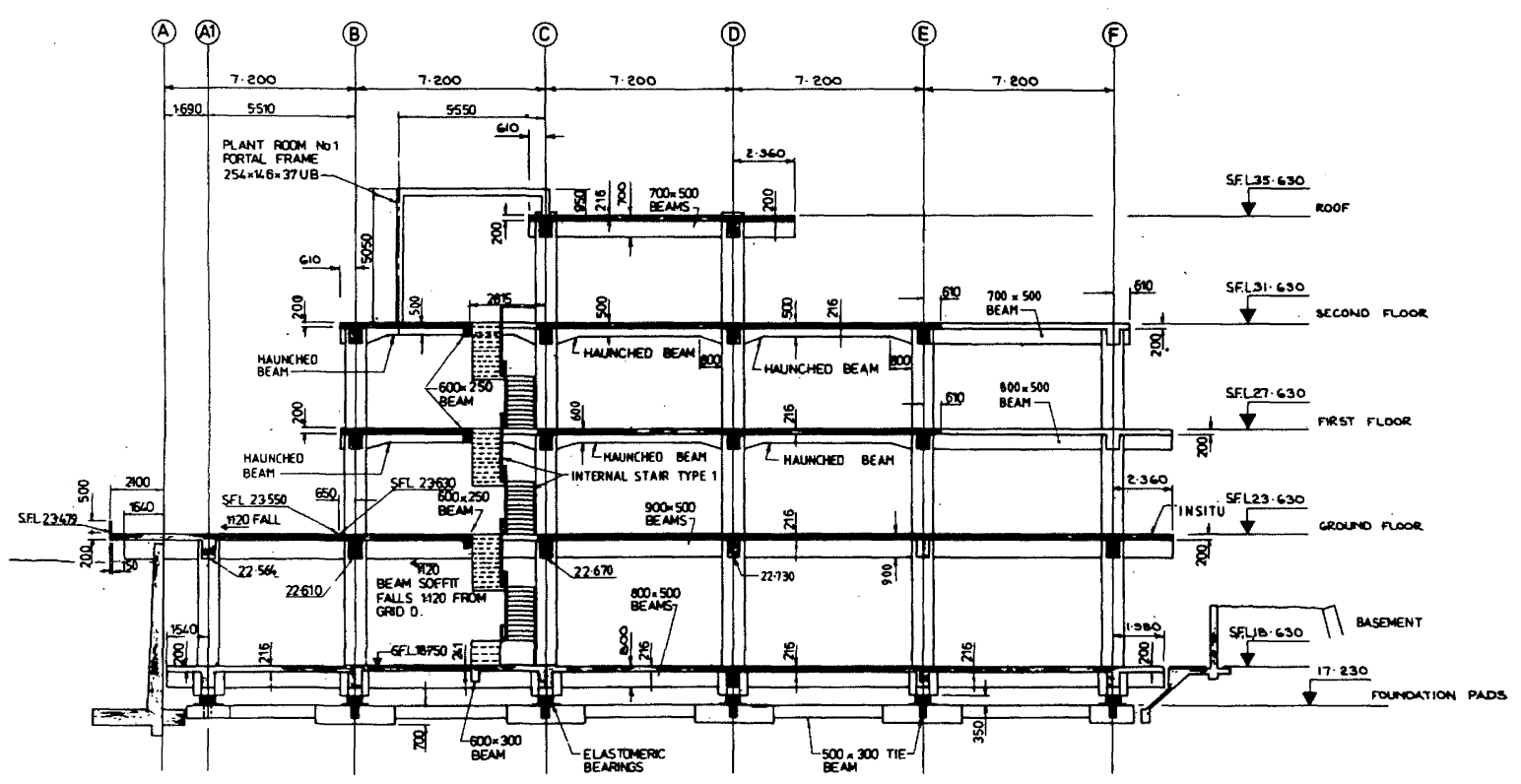

(b) Typical elevation through the building.

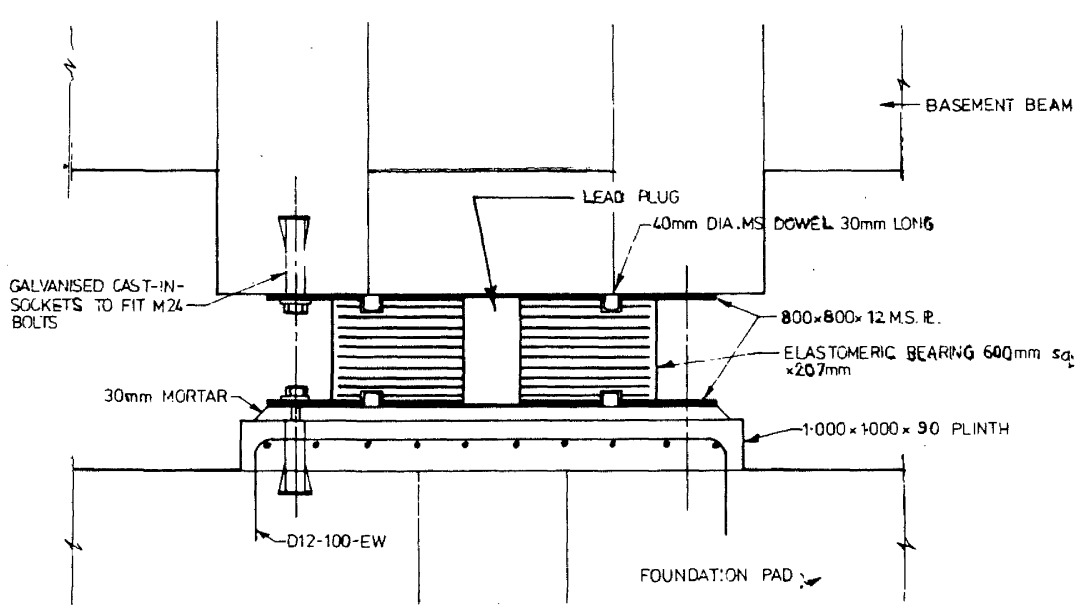

(c) Elevation through lead-rubber bearing.

Fig. 26: William Clayton Building [23]. 


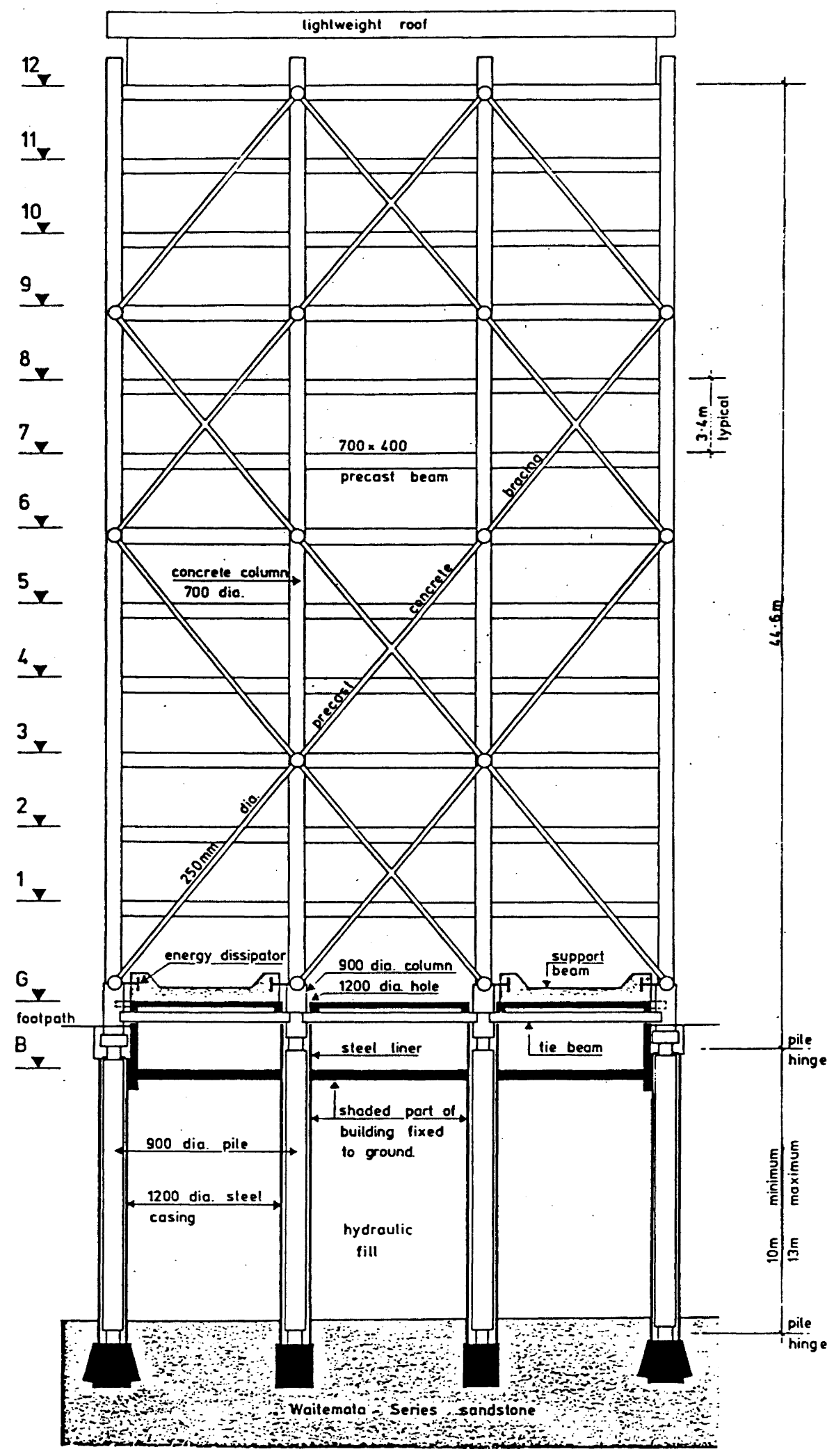

Fig. 27: Elevation of perimeter frame of Union House [24]. 


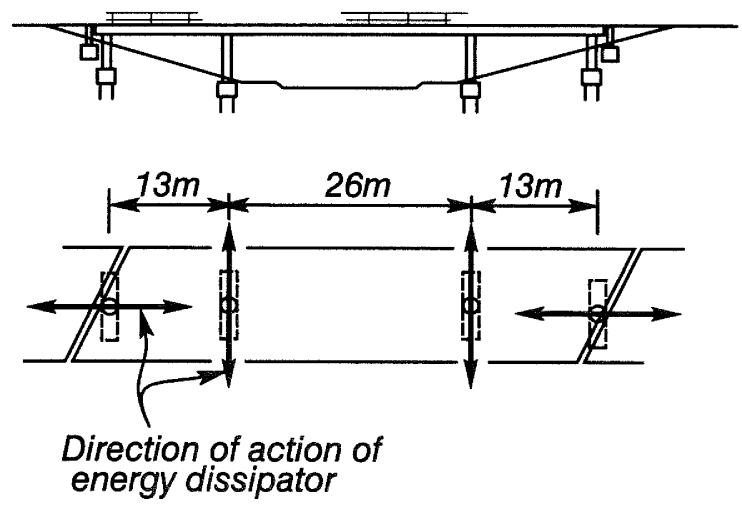

Longitudinal Elevation

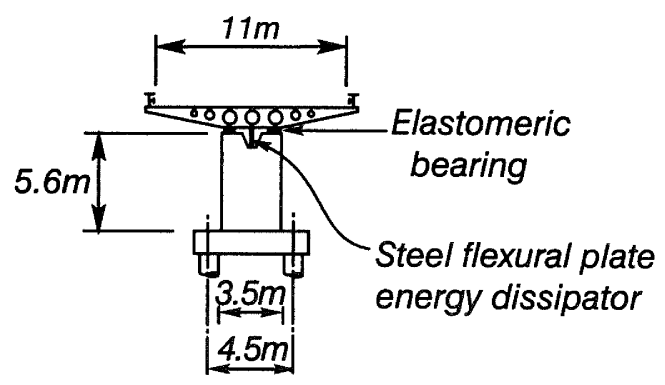

Transverse Elevation

Fig. 28: A typical seismically isolated bridge in New Zealand.

The precast concrete units are either of pretensioned prestressed or reinforced concrete (solid slabs, voided slabs, rib slabs, single tees or double tees), and generally act compositely with a cast-in-place concrete topping slab of at least $50 \mathrm{~mm}$ thickness and containing at least the minimum reinforcement required for slabs. Alternatively, precast concrete ribs spaced apart with permanent formwork of timber or thin precast concrete slabs spanning between are used acting compositely with a cast-in-place concrete slab.

As well as carrying gravity loading, floors need to transfer the in-plane imposed wind and seismic forces to the supporting structures through diaphragm action. The best way to achieve diaphragm action when precast concrete floor elements are used is to place a cast-in-place reinforced concrete topping slab over the precast units.

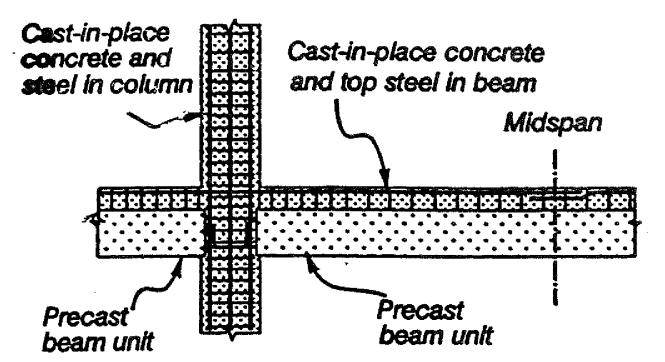

(a) System 1 - Precast Beam Units Between Columns

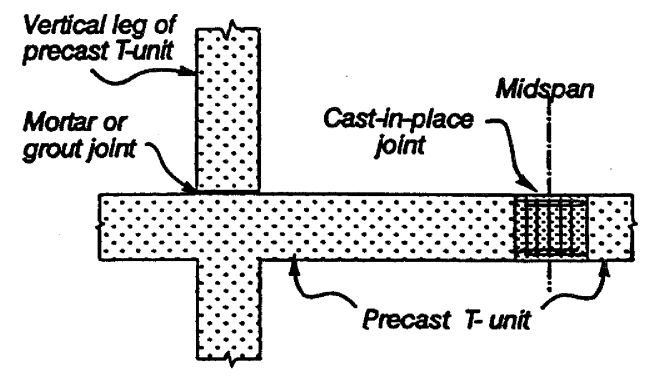

(c) System 3 - Precast T-Units
Also, adequate support of precast concrete floor units is one of the most basic requirements for a safe structure. If the seating is too narrow the floors could become dislodged and collapse as a result of imposed movements due to concrete shrinkage, creep and temperature effects, and due to elongation of beam plastic hinges during severe earthquakes. As a result the New Zealand standard for concrete design [10] recommends that either the width of seating at the end of the precast floor units be adequate or special end reinforcement details be used to prevent the end of the units becoming dislodged. A consideration amount of research work on this problem $[27,28,29]$ has been conducted at the University of Canterbury and the results have been implemented by industry in New Zealand.

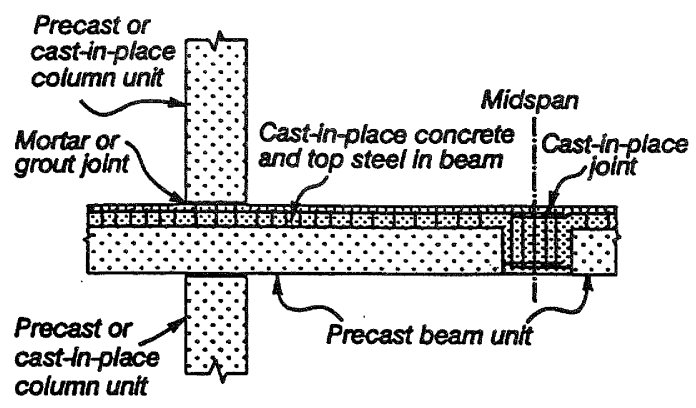

(b) System 2 - Precast Beam Units Through Columns

Fig. 29: Some arrangements of precast concrete members and cast-in-place concrete used in New Zealand for constructing reinforced concrete moment resisting frames [25, 26]. 


\subsection{Precast concrete frames}

Framed structures incorporating precast concrete elements have often performed badly in earthquakes overseas. As a result, precast concrete in moment resisting frames was shunned in New Zealand for many years. Confidence in the use of precast concrete in moment resisting frames has required the use of a capacity design approach and the development of satisfactory methods for connecting the precast elements together $[25,26]$. The precast elements of moment resisting frames are normally connected by reinforcement protruding into regions of cast-in-place reinforced concrete. If the connections between the precast elements are placed in potential plastic hinge regions, the design approach in New Zealand is to ensure that the behaviour of the connection region approaches that of a castin-place concrete structure (monolithic emulation) $[25,26]$. Three common arrangements of precast reinforced concrete members connected by cast-in-place concrete, forming ductile moment resisting multi-storey reinforced concrete frames, commonly used for strong column-weak beam designs in New Zealand, are shown in Fig. 29.

Fig. 30 shows the frame of the Price Waterhouse Building in Christchurch under construction. System 2 (see Fig. 29) was used. Fig. 31 shows the ANZ Building in Auckland, until recently, New Zealand's tallest office building, at the time of construction, using System 2.

Many of the currently used connection details for moment resisting frames have now had experimental verification [28]. The verification involved simulated seismic loading tests conducted on typical beam-column joint specimens to determine their performance. (See Fig. 32).

\subsection{Precast concrete structural walls}

Most structural walls for multi-storey buildings in New Zealand are of cast-in-place reinforced concrete, but there is significant use of precast concrete walls for smaller buildings. Precast reinforced concrete structural wall construction usually falls into two broad categories, either monolithic or jointed $[25,26]$. In monolithic wall construction the precast concrete elements are joined by "strong" reinforced concrete connections which possess the stiffness, strength and ductility approaching that of cast-inplace concrete monolithic construction. In jointed wall construction the connections are "weak" relative to the adjacent wall panels and therefore govern the strength and ductility of the building.

In jointed construction, the connection of precast reinforced concrete components is such that planes of significantly reduced stiffness and strength exist at the interface between adjacent precast concrete wall panels. Jointed construction has been extensively used in New Zealand in the tilt-up construction of buildings $[25,26]$. Generally tilt-up walls are secured to the adjacent structural elements using jointed connections comprising various combinations of concrete inserts, which anchor bars to the concrete, bolted or welded steel plates or angle brackets which are anchored to the concrete, and lapped reinforcement splices within cast-inplace joining strips.

\section{SEISMIC ASSESSMENT AN UPGRADING OF OLD STRUCTURES}

\section{$5.1 \quad$ Introduction}

The developments in seismic design standards through the years have brought about the realization that many structures in New Zealand designed before about 1976 may be deficient according to the seismic requirements of current design standards. The need for the seismic assessment of "old" building structures, and to upgrade (retrofit) if necessary, has been emphasized by the damage caused by many recent major earthquakes overseas. For example, the $\mathrm{M}=7.2$ earthquake which struck Kobe, Japan in 1995 badly damaged many buildings and bridges. However, the damage to reinforced concrete buildings in that earthquake was much more severe for buildings built before the current Japanese seismic code came into effect in 1981. Most buildings built after 1981 suffered only minor damage.

The structural deficiencies of many existing reinforced concrete structures designed to early codes in New Zealand and other countries are generally not just a result of inadequate strength. For example, the longitudinal reinforcement present in many existing structures results in a horizontal load strength which approaches or exceeds that required by current seismic design standards for ductile structures. The poor structural response during severe earthquakes is normally due to a lack of a capacity design approach to ensure the formation of an appropriate mechanism of post-elastic deformation and/or to poor detailing of reinforcement, which means that the available ductility of the structure may be inadequate to withstand the earthquake without collapse.

Analyses of existing typical early reinforced concrete building frames, designed in New Zealand prior to the mid1970's have revealed several possible problem in behaviour during future severe earthquakes [30, 31, 32]. Typical problems are:

1. Inadequate flexural strength of members, typically columns, due to insufficient longitudinal reinforcement.

2. Inadequate anchorage of longitudinal reinforcement in beam-column joint regions and lap splices placed in potential plastic hinge regions of members.

3. Inadequate transverse reinforcement in beams and columns to provide the necessary shear resistance, confinement of concrete, and restraint against buckling of longitudinal reinforcement (see Fig. 33.)

4. Inadequate anchorage of transverse reinforcement

5. Inadequate shear strength of beam-column joints due to lack of shear reinforcement.

6. Inadequate strength of footings and/or piles. 

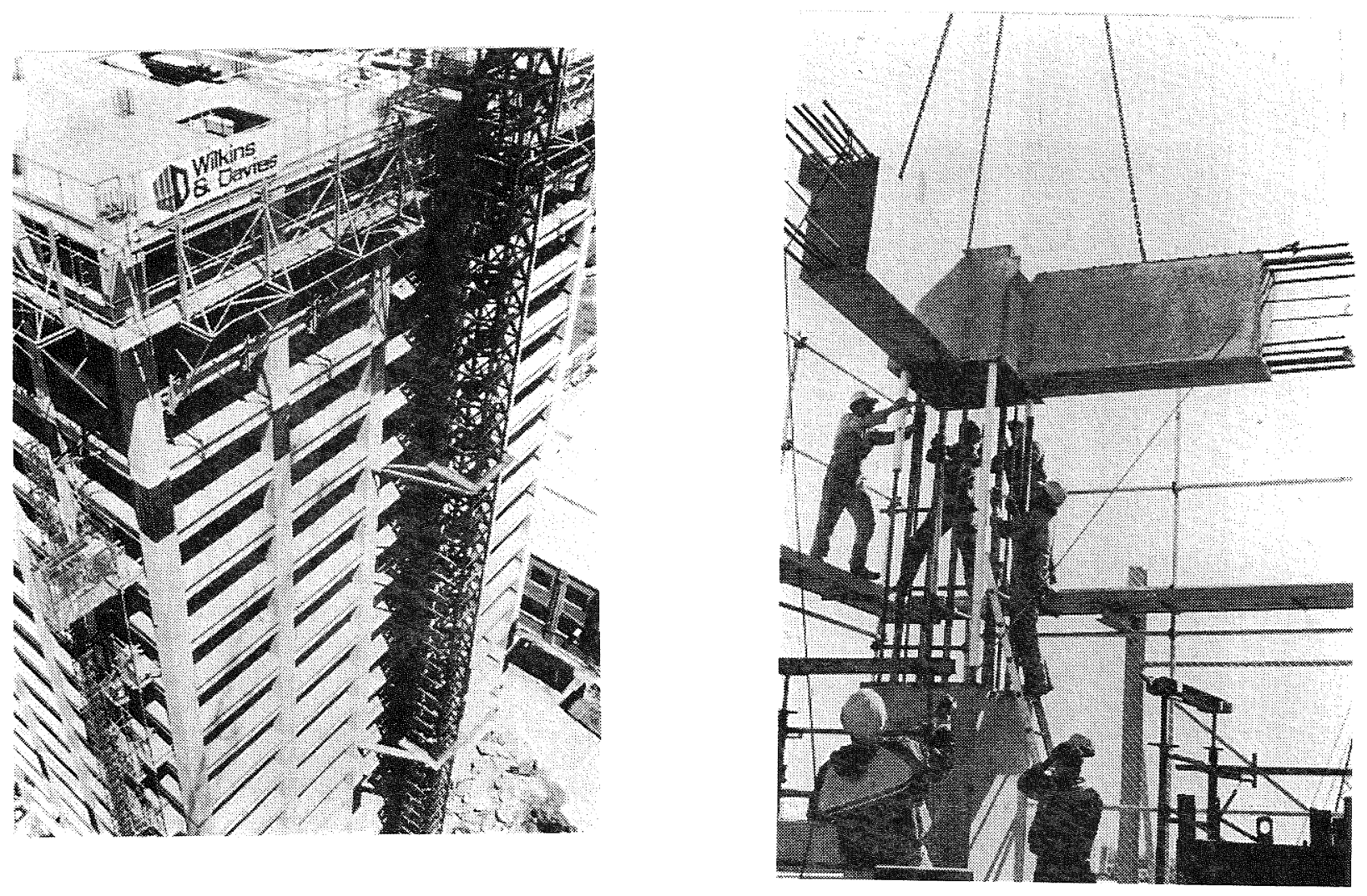

Fig. 30: Construction of the Price Waterhouse Building in Christchurch using System 2.
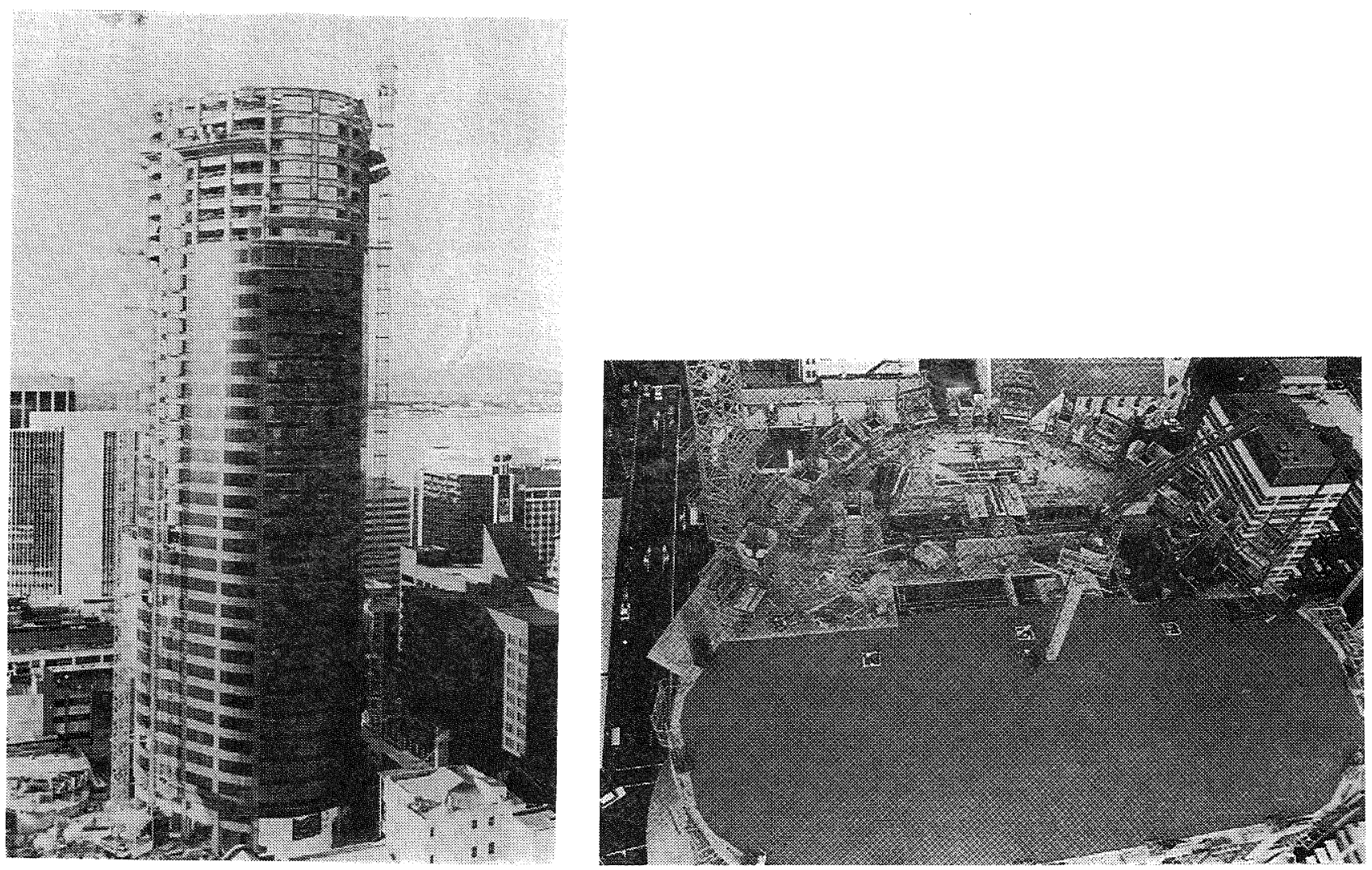

Fig. 31: Construction of the $152 \mathrm{~m}$ tall ANZ Building in Auckland using System 2. 


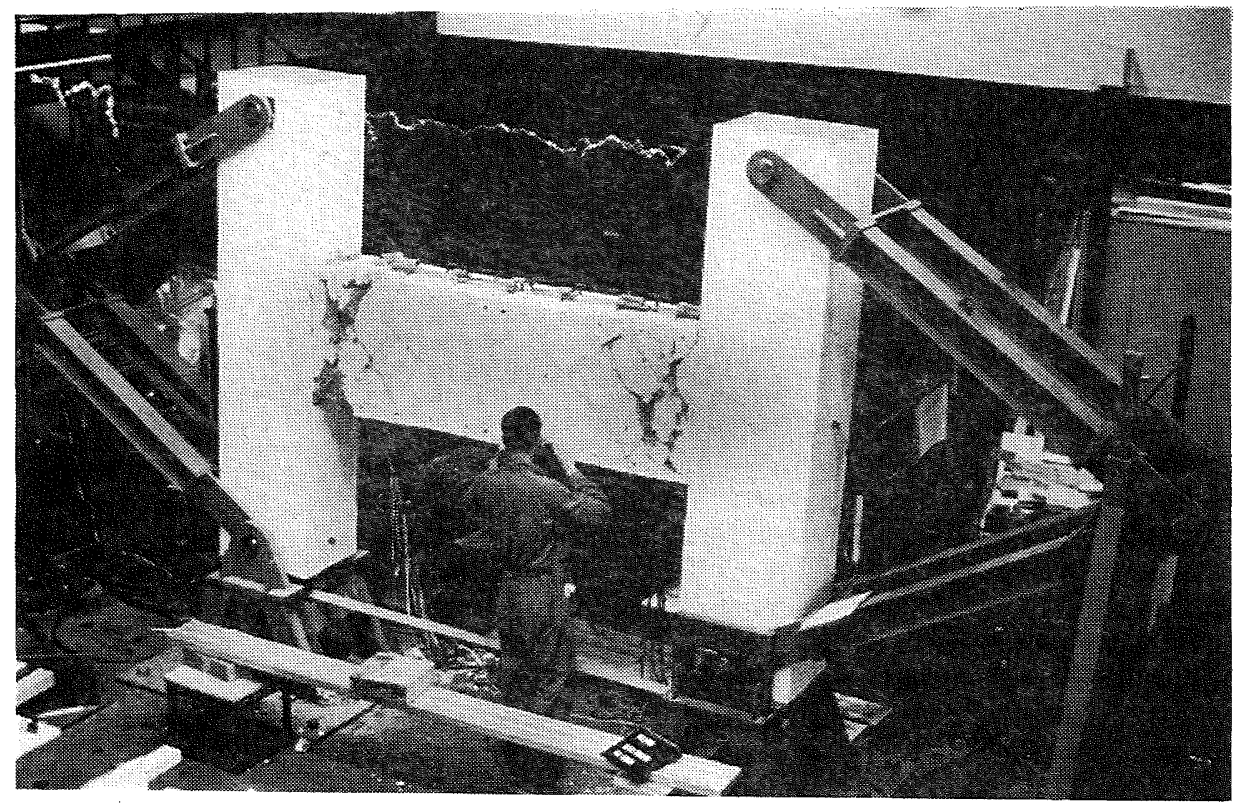

Fig. 32: Simulated seismic load test on a mid-span connection between precast concrete elements [28].

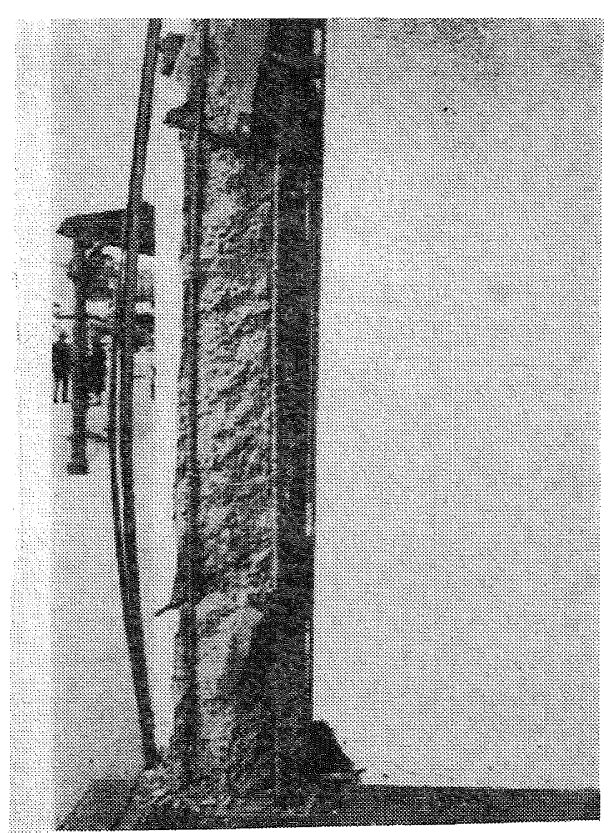

Fig. 33: Reinforced concrete column with poor transverse reinforcement damaged in the 1931 Hawke's Bay Earthquake. 


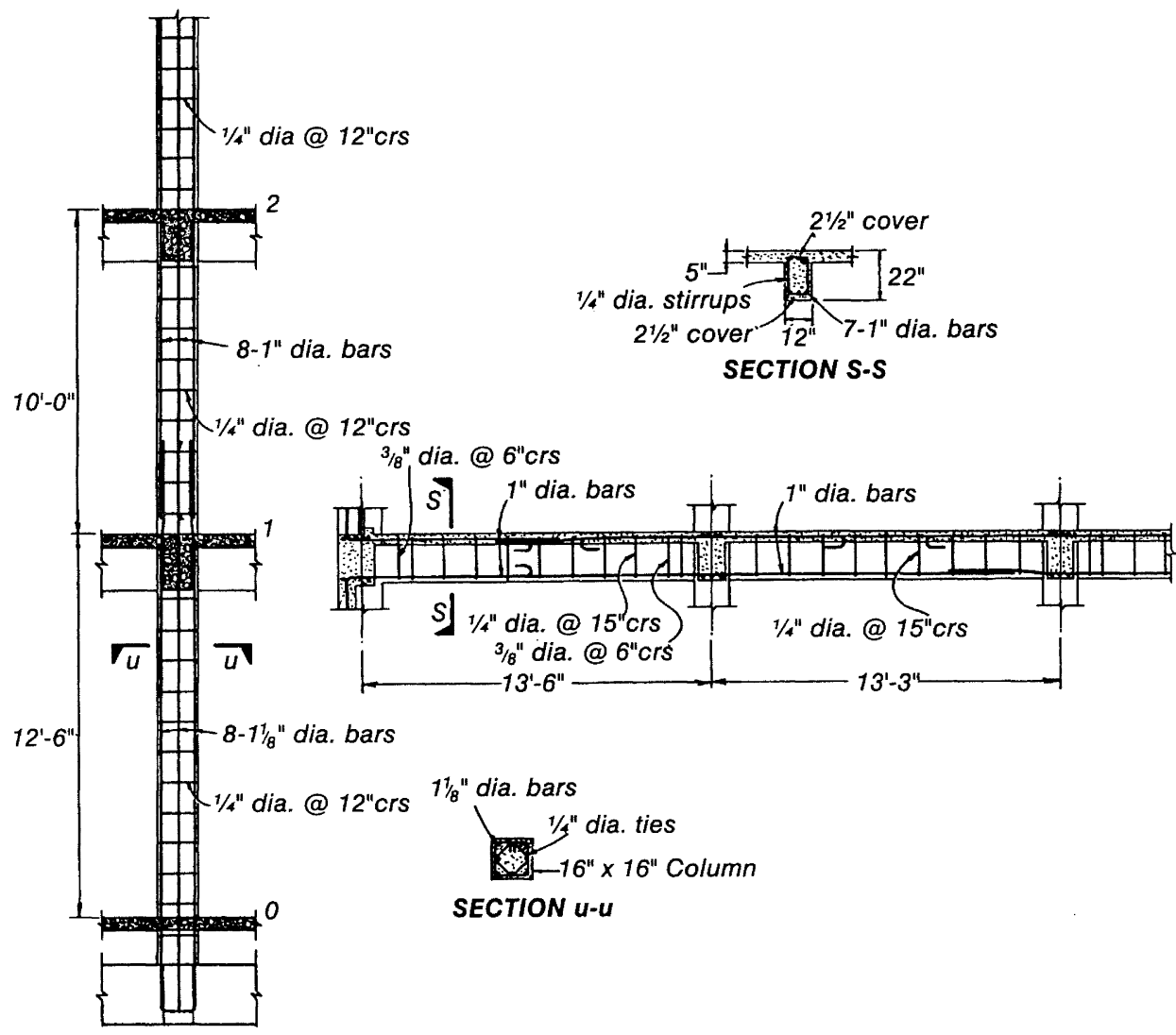

Fig. 34: Details of typical reinforcement in a reinforced concrete moment resisting frame designed in the late 1950's in New Zealand.

As an example, Figure 34 shows typical details of beam and column reinforcement in a building frame, which was constructed in New Zealand in the late 1950's. As with many building structures designed to early codes, the reinforcing details are adequate for gravity and wind loads but some of the details are inadequate for earthquake forces if ductile behaviour is required. All of the previously listed shortcomings are present in various parts of the structure shown in Figure 34.

\subsection{Assessment}

There has been increased activity in many countries in the seismic assessment of old buildings and in retrofitting where necessary to improve seismic performance. The decision to retrofit has normally been made by comparing the details of the as-built structure with the requirements of current seismic standards. The emphasis in these retrofit projects has been to bring structures up to a proportion of current standard requirements by the provision of additional strength and/or ductility. However, the evidence of tests and analysis of existing structures, and of observed earthquake damage, is that not all structures designed before the current generation of standards will respond poorly to severe earthquakes. For example, many existing structures have a horizontal force strength greater than expected by the designer (overstrength) due to a number of reasons.

Seismic assessment to determine the earthquake risk associated with the stock of older building structures in New Zealand (generally pre-1976) requires an agreed screening procedure, a more detailed assessment procedure for use when necessary, and a catalogue of available retrofit methods, for structures constructed of all materials. It is to be noted that vulnerable older buildings are not simply those constructed of unreinforced masonry.

A detailed assessment procedure for the seismic assessment of existing reinforced concrete frames has been suggested by Priestley and Calvi [30] and by Park [31]. The suggested procedure is based on determining the horizontal load strength and ductility of the critical post-elastic mechanism of deformation of the structure. Once the available horizontal load strength and ductility of the structure has been established, reference to the current code seismic acceleration response spectra for earthquake loading then enables the designer to assess the seismic risk. The procedure uses recent analytical and experimental evidence of the behaviour of elements and joints subjected to simulated seismic loading $[30,32]$. The experimental information obtained included the 
interactions between the shear strength of members or joints and flexural ductility, and the performance of lap-splices and anchorages.

\subsection{Retrofit Methods}

\subsubsection{General}

In most cases, structures are retrofitted to achieve an increase in the strength and/or ductility and stiffness. Possible retrofit measures need to be carefully assessed to ensure that the seismic characteristics of the structure will be improved. Care must be taken to be certain that the retrofit does not simply result in the problem being shifted to other critical regions of the structure. Typical retrofit methods for buildings include:

(a) Adding new structural steel bracing, either as diagonal bracing within the existing frames or as trusses placed vertically up the structure.

(b) Adding new reinforced concrete walls either as in-fills placed within existing frames or as walls placed vertically up the structure.

(c) Jacketing (encasing) existing elements by new materials.

(d) Adding seismic isolation.
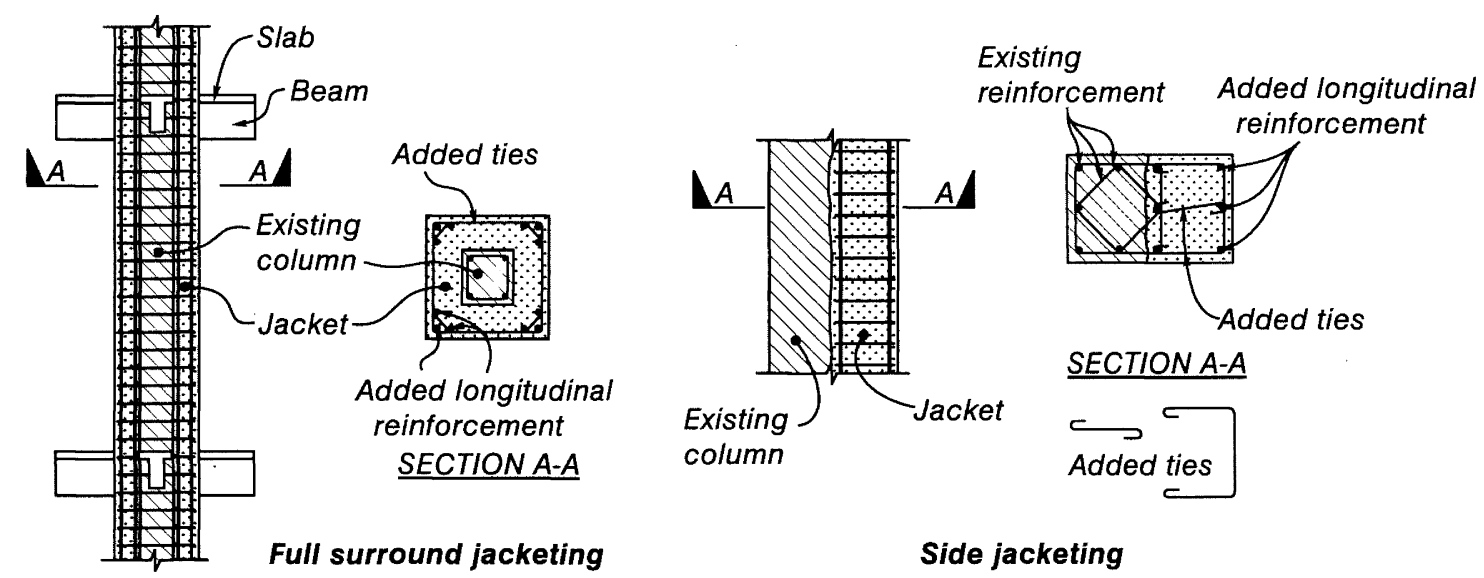

Side jacketing

(a) Reinforced Conrete Jackets

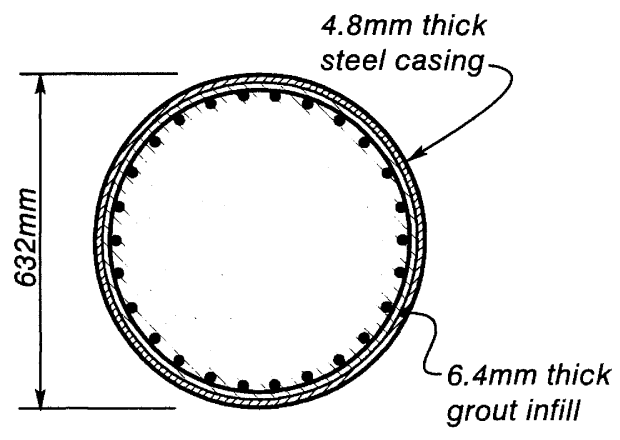

(b) Grouted site welded circular thin steel jacket

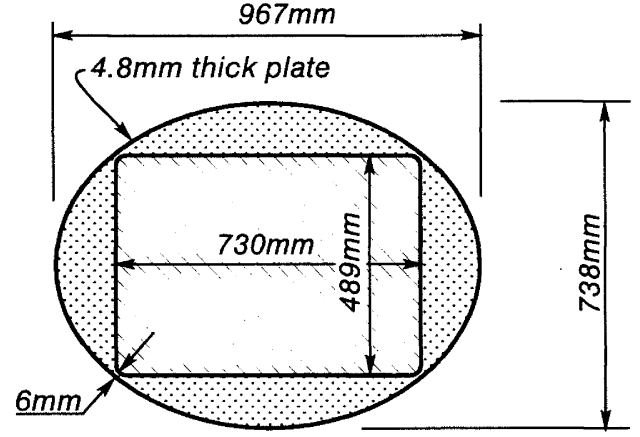

(c) Site welded elliptical thin steel jacket with concrete infill

Fig. 35: Some methods for retrofitting columns.

\subsubsection{Retrofitting columns}

Columns are particularly vulnerable elements in buildings. Several methods for increasing the strength and/or ductility of existing columns have been developed, tested and used in the United States, Japan, New Zealand and other countries. These methods include jackets of new concrete containing new longitudinal and transverse reinforcement [33], grouted site welded circular thin steel jackets [34], site welded elliptical thin steel jackets filled with concrete [34], grouted stiffened or built-up rectangular steel jackets, grouted or not grouted composite fibreglass/epoxy jackets $[34,35]$ or carbon fibre jackets, prestressing steel wrapped under tension [34] (see Fig. 35). Methods for calculating the required size of jackets are given in the above references. 
The column retrofit can be designed so as to not increase the flexural strength but to provide only additional transverse reinforcement for concrete confinement, restraint against premature buckling of existing longitudinal bars, shear resistance and restraint against bond failure of lap splices of longitudinal reinforcement. In such cases the strengthening is not continued beyond the ends of the column, so that the flexural strength of the column ends is not increased. Alternatively, the strengthening can be continued beyond the ends of the column so that the flexural strength of the column ends is increased. This alternative requires the passing of longitudinal reinforcement through the floors in the case of a building.

The use of reinforced concrete jackets can be very labour intensive, but has been widely used in Mexico City after the 1985 earthquake [33].

The most widely used technique in California for providing bridge columns with additional transverse reinforcement, but without additional longitudinal reinforcement, has been the use of thin steel jackets [34]. For circular columns the thin steel jacket is constructed slightly oversize in two semi circular halves which are welded up vertical seams in situ. The jacket is terminated about $25 \mathrm{~mm}$ from the face of the beams or footing at the column ends. The gap between the steel jacket and the column is subsequently pressure filled with a cement-based grout, which contains a small quantity of water reducing expansive additive. For rectangular columns an elliptical thin steel jacket is used to provide continuous confinement, with concrete placed between the jacket and the column. A rectangular thin steel jacket would not be so effective, due to the sides bowing out when dilation of the concrete occurs during a major earthquake, resulting in confinement applied mainly in the column corners.

The use of fibreglass/epoxy jackets for columns of buildings and bridges is becoming common in New Zealand. Typically the columns are coated with epoxy and then fibreglass sheets are wrapped around the columns and are not grouted.

\subsubsection{Retrofitting beam-column joints}

Beam-column joint regions can be retrofitted by jacketing, using either external steel or fibreglass/epoxy jacketing or jacketing with new reinforced concrete. This can be a very labour intensive and costly procedure, due to the drilling of holes through the existing joint to pass new reinforcement through, etc. One solution, which has been adopted for beam-column joints of bridge bents, has been to remove the existing concrete joint and to replace the whole joint region with new reinforced concrete.

\subsubsection{Retrofitting of footings}

Retrofitting of footings is an important consideration particularly in the seismic upgrading of bridges. Deficiencies may be due to inadequate footing strength in flexure or shear, or footing/column shear strength, or anchorage of column reinforcement, or pile capacity, or overturning resistance. An overlay of reinforced concrete, above and/or around the footing, tied to the original concrete by hooked bars epoxied into drilled holes, can be used.

\section{3 .5 \\ Use of base isolation and mechanical energy} dissipating devices

Energy dissipating devices also have significant potential for use in the retrofitting of existing structures, which have inadequate strength or ductility for seismic resistance. For example, the structure could be protected against major earthquake damage by mounting it on lead-rubber devices of the type shown in Figure 25. Dynamic analyses is required to ensure that the response of the base isolated structure is satisfactory.

An example of this technique is the recent retrofit of New Zealand Parliament House [36]. New Zealand Parliament House is a five-storey masonry bearing wall structure which was completed in 1922 (see Fig. 36a). The floors are of reinforced concrete supported on a two-way system of steel beams. The building was assessed to be an earthquake risk. It has been seismically upgraded by the enhancement of the strength of the existing structure and by the use of base isolation. The structural retrofit was completed in 1995 . Strengthening was achieved by adding reinforced concrete walls to the faces of the existing masonry walls and other means. However, this strengthening is not inherently ductile. The addition also of lead-rubber base isolators under the walls and columns at ground level of the existing building (see Fig. 36b) significantly reduces the seismic loads attracted to the building. Whilst not eliminating the need for strengthening of the existing building structure the leadrubber base isolators provide a very high level of protection against severe seismic loading.

\subsection{Ensuring the seismic security of existing structures}

It is the view of the author that the Building Act should give territorial authorities the right to require structural upgrading of buildings when found necessary by seismic assessment. It is anticipated that the Building Act will be revised shortly to make this possible.

Nevertheless, ideally it should not require regulations to enforce building owners to spend dollars on upgrading the seismic resistance of buildings found deficient. What drives the owner to retrofit should be the responsible approach. That is, there should be concern for the safety of staff and clients working in and using the building, the value of the contents of the building, and the considerable disruption to the business and other activities normally conducted in the building as a result of earthquake damage. Many businesses in Kobe, Japan did not recover after the earthquake in 1995 due to the severe economic difficulties resulting from the loss of factories and other facilities for several months.

A study group of the New Zealand National Society for Earthquake Engineering is currently preparing a document which it is anticipated will be nominated by the New Zealand Building Code Handbook as a means of compliance with the revised Building Act. A first draft of this document for the detailed assessment of reinforced concrete and structural steel moment resisting frames was released for comment by the New Zealand National Society for Earthquake Engineering in 1996 [37]. This document will be extended in the future. 


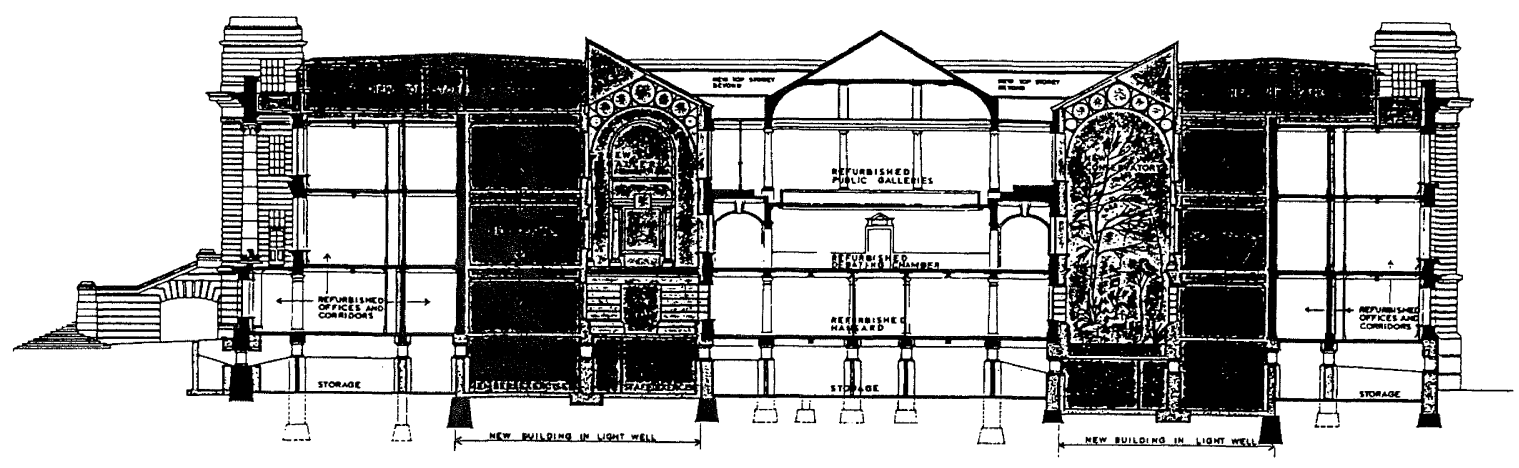

(a) Section through Parliament House.

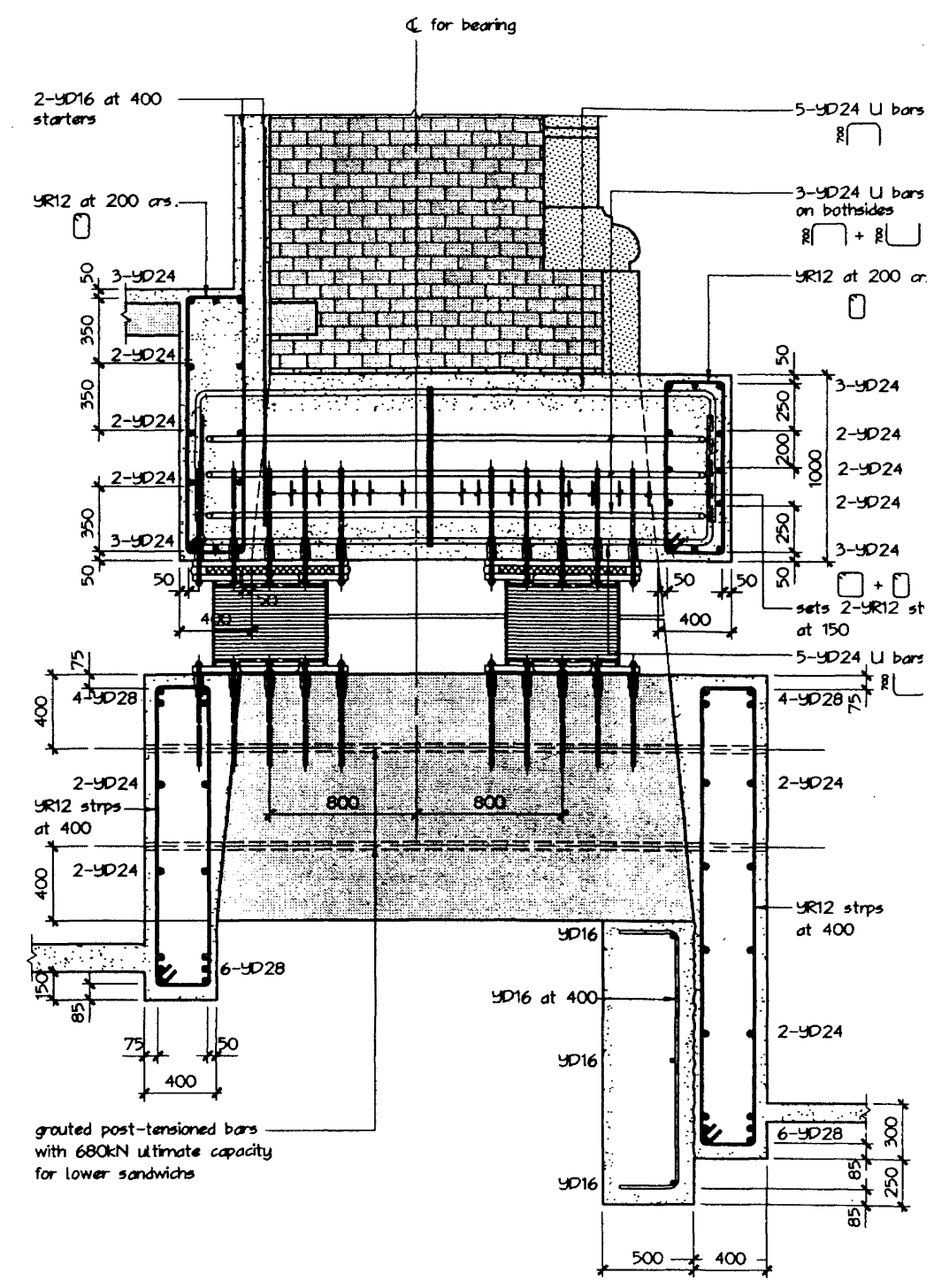

(b) Lead-Rubber bearings at north wall.

Fig. 36: New Zealand Parliament House [36]. 
The fact that New Zealand has not had a major earthquake close to an urban centre for almost 70 years should not lull building owners into a false sense of security. History tells us that a severe earthquake could occur in New Zealand at any time. Upgrades of buildings where necessary are vital to reduce the damage, economic loss and casualties caused by severe earthquakes.

\section{EARTHQUAKE RESISTANCE OF LIFELINES}

All communities have lifelines:

- Transportation - roads, railways, bridges

- Utilities - electricity, gas, water, wastewater

- Communication - telephones

The Kobe earthquake of 1995 showed the need for lifelines to have adequate seismic resistance. A community will suffer severe economic loss and disruptions if the transportation is not flowing freely and if the utilities and communications are not operating after an earthquake.

Widespread damage can occur to lifelines as a result of soil deformations and liquefaction of soft soils, reclamations and saturated sandy soils. For buried pipes and the services, provision of adequate axial displacement capacity and lateral flexibility is often more important than strength in these situations. Underground lifelines that cross boundaries between soft soils and rock, and buried services entering a building, are particularly vulnerable.

The possible failure of lifelines highlights the desirability of providing alternative lifeline routes that pass through geologically different and preferably less vulnerable areas. This particularly applies to existing lifelines that have not been designed to ensure ductile behaviour, or that are vulnerable to large ground displacements.

The needs for adequate attention to lifelines in New Zealand was emphasised by the report of the New Zealand reconnaissance team which went to Kobe after the 1995 earthquake [7]. Those preliminary assessments have been developed further in a report outlining findings and observations with regard to lifelines and other infrastructural items as a result of subsequent visits to Kobe and further analysis [38]. As well as mitigation measures that need to be taken to reduce the vulnerability of lifelines to earthquake damage, the report emphasises the necessity of having response and recovery plans in place to increase awareness and preparedness for the effects of a major earthquake.

The establishment of Lifelines Groups in Christchurch [5], and in other parts of New Zealand over the last few years, means that the lifelines in these areas should be better prepared to cope with a major earthquake. Particularly encouraging is the degree of co-operation that has developed between the various utility authorities and the advance emergency planning that is being undertaken.

\section{CONCLUSIONS}

1. New Zealand has had major damaging earthquakes in the past. It is fortunate that almost 70 years has elapsed, since the 1931 Hawke's Bay earthquake, without a major earthquake striking an urban area. However, New Zealanders must not be complacent in their consideration of earthquakes. The attitude or belief "that it will not happen to us" or "it will most likely only occur in Wellington" needs to be eradicated. There is a $65 \%$ probability that Christchurch will be effected by a major earthquake over the next 50 years.

2. Buildings and bridges designed and constructed according to modern seismic standards in general will survive major earthquakes well, as demonstrated by major earthquakes in developed countries overseas. This justifies the design and construction provisions of current New Zealand standards (which are very much more severe than older pre mid-1970s standards) and emphasizes the need to enforce current standards strictly.

3. Good seismic design of building and bridge structures involves consideration of the following aspects:

- Structural configuration : the arrangements of structural members of buildings should be symmetrical and regular as far as possible, both vertically and horizontally.

- Appropriate mechanisms of post-elastic deformation : the relative strengths of modes of failure and members should be such as to ensure a desirable mode of post-elastic deformation of the structure during earthquakes. This aim can be achieved by the capacity design approach.

- Adequate ductility : the reinforcement of concrete structures should be detailed so as to ensure adequate ductility in the yielding regions during major earthquakes.

- Displacement control : the interstorey drift of buildings during earthquakes should not lead to excessive damage or loss of integrity of the structure.

4. The extensive use of precast concrete in buildings in New Zealand has required innovative design of connection regions for resistance to earthquakes.

5. The earthquake hazard of older structures (pre mid1970's) is evident. Many of those older buildings and bridges in New Zealand may need retrofitting. This applies to structures of reinforced concrete and structural steel, as well to unreinforced masonry.

6. The need for lifelines of cities to have adequate seismic resistance is very apparent. A city will suffer severe 
economic loss and disruptions if the utilities are not operating and transport is not flowing freely after an earthquake.

\section{ACKNOWLEDGMENTS}

The author acknowledges the contributions from many colleagues and postgraduate students at the University of Canterbury and from many other members of the New Zealand National Society for Earthquake Engineering. Thanks are due to Miss Catherine Price for the word processing of this manuscript.

\section{REFERENCES}

1. G R Stevens, "New Zealand Adrift", $A H$ and $A$ W Reed, Wellington 1980, $442 \mathrm{pp}$.

2. G A Eiby "Earthquakes", Heineman Educational Books, Auckland, 1980, 209 pp.

3. J Cousins, "Preparing for the Next Big Quake", Build, Building Research Association of New Zealand, May/June 1999, pp 26-29.

4. M D Yetton, A Wells and N J Traylen, "The Probability and Consequences of the Next Alpine Fault Earthquake", Earthquake Commission Research Report 95/153, Wellington, 1998, $161 \mathrm{pp}$.

5. Christchurch Engineering Lifelines Group, "Risks and Realities - A Multi-Disciplinary Approach to the Vulnerability of Lifelines to Natural Hazards", Centre for Advanced Engineering, University of Canterbury, $1997,311 \mathrm{pp}$.

6. D McG Elder, I F McCahon and M D Yetton, "The Earthquake Hazard in Christchurch: A Detailed Evaluation", Earthquake Commission Research Report, Wellington, 1991, $131 \mathrm{pp}$ plus appendices.

7. R Park, I J Billings, G C Clifton, J Cousins, A Filiatrault, D N Jennings, L C P Jones, N D Perin, S L Rooney, J Sinclair, D D Spurr, H Tanaka and G Walker, "The Hyogo-ken Nanbu Earthquake (The Great Hanshin Earthquake) of 17 January 1995 . Report of the NZNSEE Reconnaissance Team", Bulletin of the New Zealand National Society for Earthquake Engineering, Vol. 28, No. 1, March 1995, pp 1-98.

8. R Park, and T Paulay, "Reinforced Concrete Structures", John Wiley, New York, 1975, 769 pp.

9. Standards Association of New Zealand, "General Structural Design and Design Loadings for Buildings, NZS 4203:1992", Wellington, New Zealand.

10. Standards New Zealand, "The Design of Concrete Structures NZS 3101 : Part 1: 1995" and "Commentary on the Design of Concrete Structues NZS 3101 : Part 2 : 1995", and "Amendment No. 1 to NZS 3101 Parts 1 and 2, 1998", Wellington, New Zealand.
11. R Park, "Ductile Design Approach for Reinforced Concrete Frames", Earthquake Spectra, Professional Journal of the Earthquake Engineering Research Institute, Vol. 2, No. 3, May 1986, pp 565-619.

12. T Paulay, "The Design of Ductile Reinforced Concrete Structural Walls for Earthquake Resistance", Earthquake Spectra, Professional Journal of the Earthquake Engineering Research Institute, Vol. 2, No. 4, October 1986, pp 783-824.

13. J P Hollings, "Reinforced Concrete Seismic Design", Bulletin of New Zealand National Society for Earthquake Engineering, Vol. 2, No. 3, 1969, pp 217 250.

14. T Paulay and M J N Priestley, "Seismic Design of Reinforced Concrete and Masonry Buildings", John Wiley, New York, 1992, 744 pp.

15. R Park, "Review of Code Developments for Earthquake Resistance Design of Concrete Structures in New Zealand", Bulletin of New Zealand National Society for Earthquake Engineering, Vol. 14, No. 4, December 1981, pp 177-208.

16. T Paulay and J R Binney, "Diagonally Reinforced Coupling Beams of Shear Walls", Shear in Reinforced Concrete, ACI Special Publication SP 42, Detroit, 1974, Vol. 1, pp 579-598.

17. S Watson, F A Zahn and R Park, "Confining Reinforcement for Concrete Columns", Journal of Structural Engineering, American Society of Civil Engineers, Vol. 120, No. 6, June 1994, pp 1798-1824.

18. M J N Priestley and M J Kowalsky, "Direct Displacement-Based Seismic Design of Concrete Buildings", Bulletin of the New Zealand Society for Earthquake Engineering, Vol. 33, No. 4, December 2000, pp 421-444.

19. Transit New Zealand, "Bridge Manual", 1994 plus amendment No. 1 June 1995, Wellington.

20. M J N Priestley and R Park, "Strength and Ductility of Concrete Bridge Columns Under Seismic Loading", Structural Journal of American Concrete Institute, Vol. 84, No. 1, Jan-Feb 1987, pp 61-76.

21. R I Skinner, R G Taylor and W H Robinson, "Hysteretic Dampers for the Protection of Structures from Earthquakes", Bulletin of the New Zealand National Society for Earthquake Engineering, Vol. 13, No. 1, March 1980, pp 22-36.

22. R I Skinner, W H Robinson and G McVerry, "An Introduction to Seismic Isolation", John Wiley, Chichester, 1993.

23. L M Megget, "Analysis and Design of a Base-Isolated Reinforced Concrete Frame Building", Bulletin of the 
New Zealand National Society for Earthquake Engineering, Vol. 11, No. 4, December 1978, pp 245 254.

24. P R Boardman, B J Wood and A J Carr, "Union House A Cross-Braced Structure With Energy Dissipators", Bulletin of the New Zealand National Society for Earthquake Engineering, Vol. 16, No. 2, June 1998, pp 83-97.

25. R Park, "A Perspective on the Seismic Design of Precast Concrete Structures in New Zealand", Journal of the Prestressed/Precast Concrete Institute, Vol. 40, No. 3, May-June 1995, pp 40-60.

26. Study Group of the New Zealand Concrete Society and New Zealand National Society for Earthquake Engineering, "Guidelines for the Use of Structural Precast Concrete in Buildings", Centre for Advanced Engineering, University of Canterbury, New Zealand, August 1991, pp 174.

27. R C Fenwick and A Fong, "The Behaviour of Reinforced Concrete Beams Under Cyclic Loading", Bulletin of the New Zealand National Society for Earthquake Engineering, Vol. 12, No. 2, June 1979, pp 158-167.

28. J I Restrepo, R Park and A H Buchanan, "Tests on Connections of Earthquake Resisting Precast Reinforced Concrete Perimeter Frames of Buildings", Journal of the Prestressed/Precast Concrete Institute, Vol. 40, No. 4, July-August 1995, pp 44-61.

29. M Herlihy and R Park, "Detailing Precast Flooring Systems to Survive Loss of Support", Proceedings of the New Zealand Concrete Society Technical Conference, TR18, 1996, pp 130-139.

30. M J N Priestley and G M Calvi, "Towards a Capacity Design Assessment Procedure for Reinforced Concrete Frames", Earthquake Spectra, Vol. 7, No. 3, pp 413437.

31. R Park, "A Static Force-Based Procedure for the Seismic Assessment of Existing Reinforced Concrete Moment Resisting Frames", Bulletin of the New Zealand National Society for Earthquake Engineering, Vol. 30, No. 3, September 1997, pp 213-226.

32. S Hakuto, $\mathrm{R}$ Park and $\mathrm{H}$ Tanaka, "Retrofitting of Reinforced Concrete Moment Resisting Frames", Research Report 94-4, Department of Civil Engineering, University of Canterbury, 1995.

33. M Rodriguez and R Park, "Repair and Strengthening of Reinforced Concrete Buildings for Earthquake Resistance", Earthquake Spectra, Professional Journal of the Earthquake Engineering Research Institute, Vol. 7, No. 3, August 1991, pp 439-459.

34. M J N Priestley, F Seible and G M Calvi, "Seismic Design and Retrofit of Bridges", John Wiley, New York 1996, 686 pp.
35. M J N Priestley, E Fyfe and F Seible, "Column Retrofit Using Fibreglass - Epoxy Jackets”, First Annual Seismic Research Workshop, California Department of Transportation, Sacramento, December 1991, pp 217 224.

36. R A Poole and J E Clendon, "New Zealand Parliament Buildings: Seismic Protection by Base Isolation", Proceedings of the Pacific Conference on Earthquake Engineering, Vol. 3, Auckland, November 1991, pp 1333.

37. New Zealand National Society for Earthquake Engineering, "The Assessment and Improvement of the Structural Performance of Earthquake Risk Buildings", May 1996, pp 116.

38. D R Brunsdon, N R Britton, R J Carter, R F Crimp, E F Gates, M A Gordon, G J Hughson, AJW Lamb, P D Leslie, G Wabnitz and A C Watson, "Lessons for New Zealand Lifelines Organisations from the 17 January 1995 Great Hanshin Earthquake", Bulletin of the New Zealand National Society for Earthquake Engineering, Vol. 29, No. 1, March 1996, pp 1-55. 